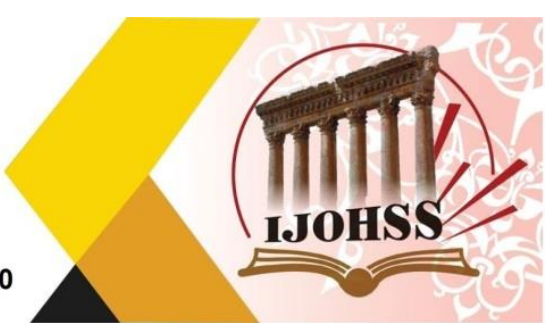

\title{
التحقيق النحوي في الأسماء المعربة عند نحويي القرنين السابع والثامن الهجرينين الهين الهريه
}

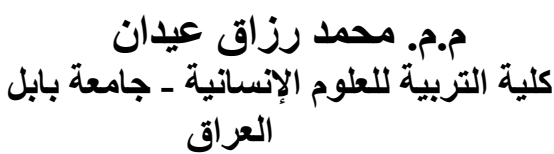

العراق مان

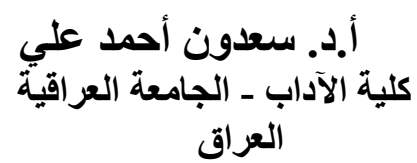

الملّمص

من الظو اهر التي شاعت في المصادر النحويّة ظاهرة تعدّد الآراء النحويّة، واختلاف النحويين في عدد من المسائل النحويّة، فنشرع عدد منهم في عرض تللك المسائل الخلافيّة و استقصساء أدلّتها، و الوقوف على حقيقتها، فظهر ما يُسمّى بـ(التحقيق النحوي)، الذي يقوم على إثبات الرأي النحوي، وتحليله، واستقصـاء أدلّته، وقد كان

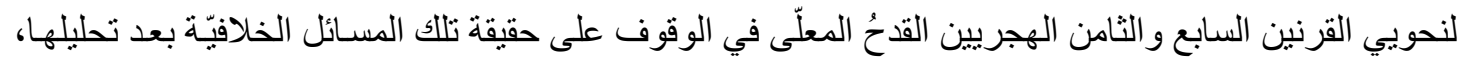

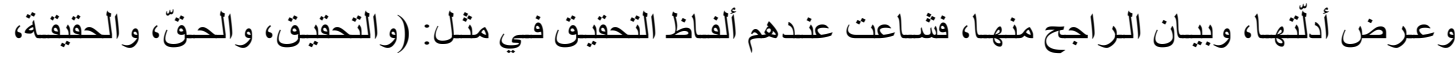
و المحققون) ونحو ذللك، وقد التزم البحث المسائل الخلافيّة في الأسماء المعربـة التي تضمّنت ألفاظ التحقيق عند

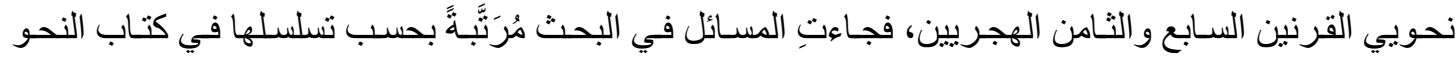
الو افي، إذ تبدأ المسألة بذكر العنوان العام لها، ثمّ استيفاء آراء النحويين فيها، و الموازنة بين تلك الآر اء بعرض الحجج النقليّة والعقليّة لكلّ رأي، وما يتصل بذلك من أمور تعين على التحقيق و الترجيح، كالمعنى ومو افقته لها، وأحكام الكلام وجريانه على قو اعد العرب في كلامهم. وقد اعتمد البحث على أمّات المصـادر النحويّة القديمـة

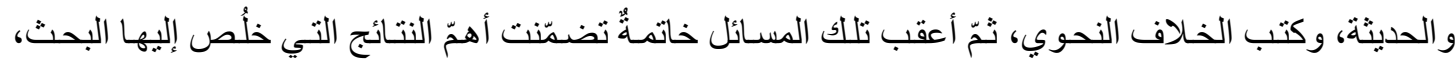
فقائمة بأسماء المصادر و المراجع . ولبه

الكلمات المفتاحية: التحقيق النحوي، الأسماء المعربة، نحويي القرنين السابع و الثامن الهجريين. 


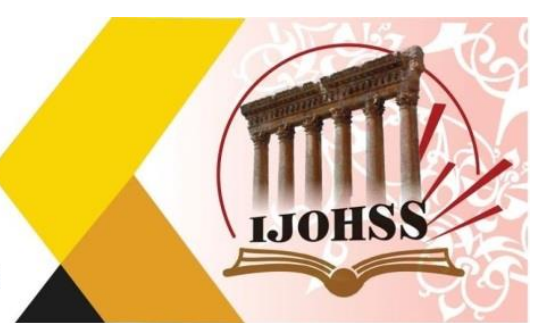

\title{
The Grammar in the Names of the Neighborhood in the Nationwide and the Hexagonal Sectors
}

Prof. Dr. Saadoon Ahmed Ali

\author{
Assist. Lect. Muhammad Razaq Idan
}

\begin{abstract}
One of the phenomena in the grammar symptoms of the grammar and the difference of the grapes in a number of grammatical issues, a number of more than the two stories have been made in the presentation of those translating issues and the adoption of the accuracy and to take their reality. The seventh and eighth hexagon lists were the mugged in the stand to be the right of their matters after their analysis, presentation and evidence of the most successful, including the investigation, the right to the investigation, in the cases that included the search for the first injury in the nourishing of the seventh century and the tremor.
\end{abstract}

Keywords: grammatical investigation, Arabized names, grammar in the seventh and eighth Hijri centuries. 
2020 سبتمبر

ISSN: $2415-4822$
Volume (15)
العدد (15)

September 2020

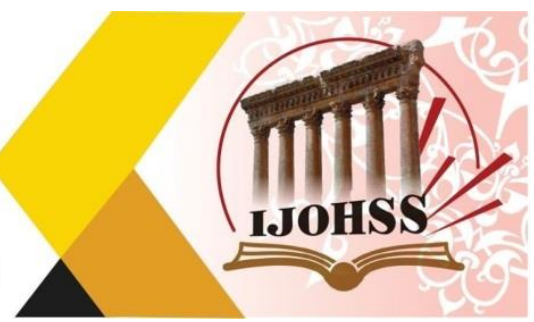

المسألة الأولى: وقوع الجملة فاعلًا

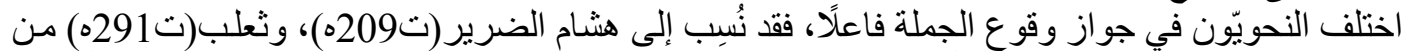

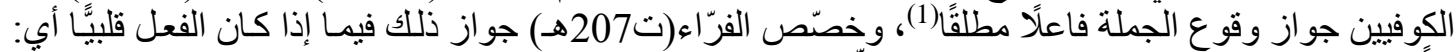

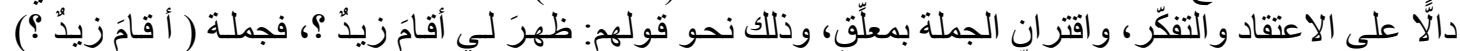

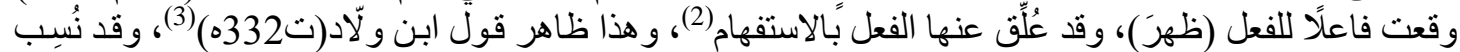

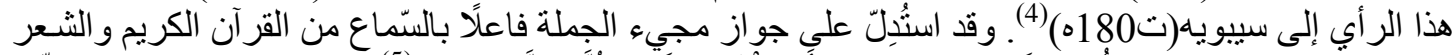

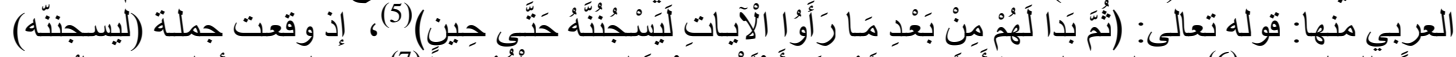

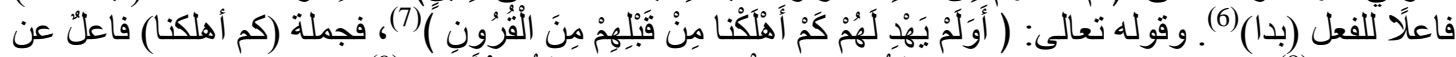

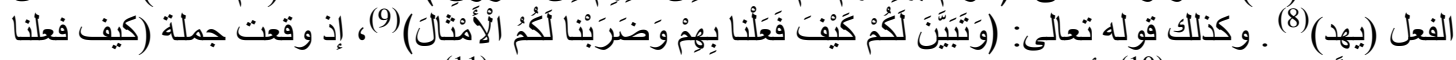

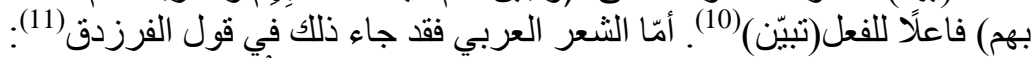

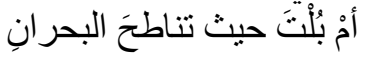

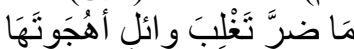

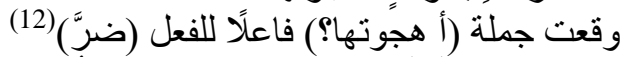

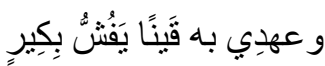

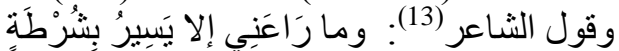

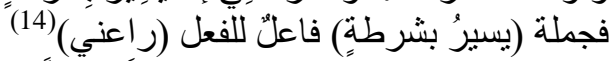

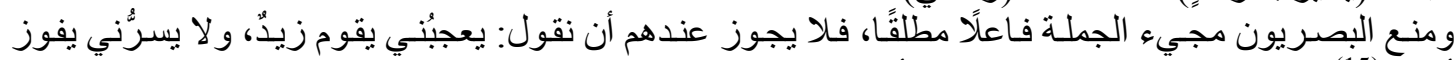

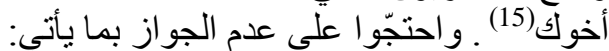

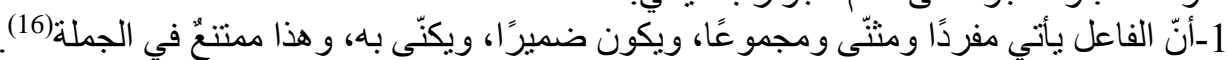

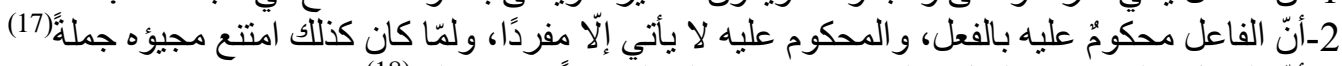

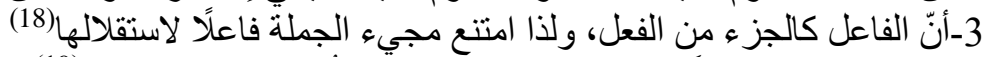

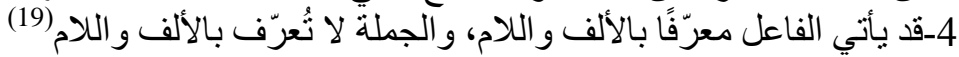

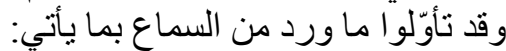

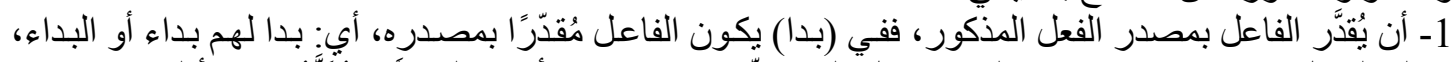

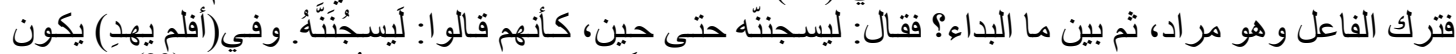

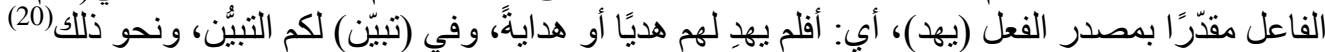

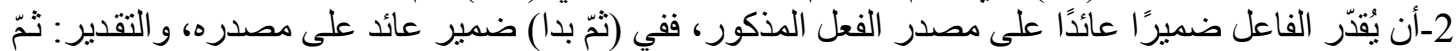

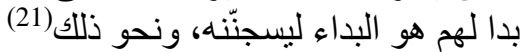

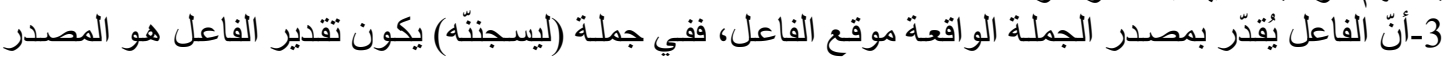

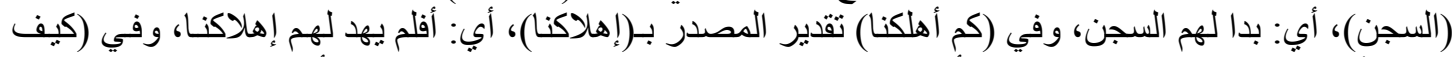

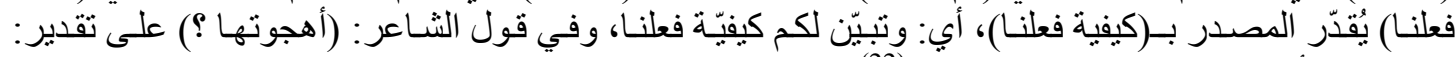

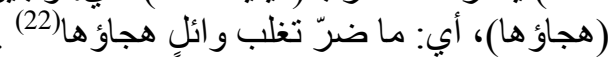

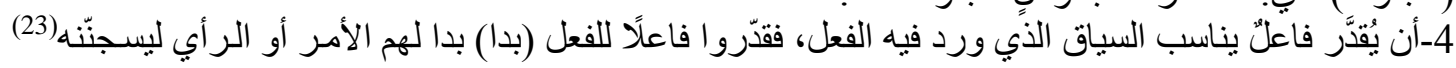

5ـ قدرّوا (أنْ) قبل جملة (يسير بشرطة) في البيت الثعري؛ لينسبك مصدرٌ يقع فاعلًا للفعل قبله، و التقدير : ومـا

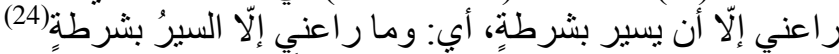

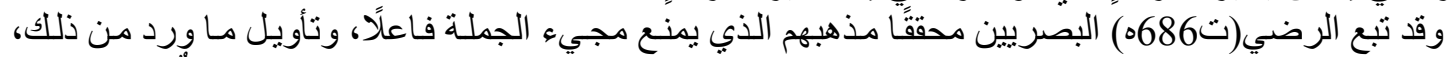

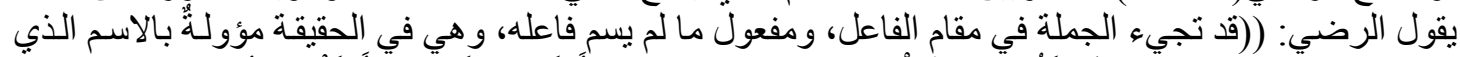

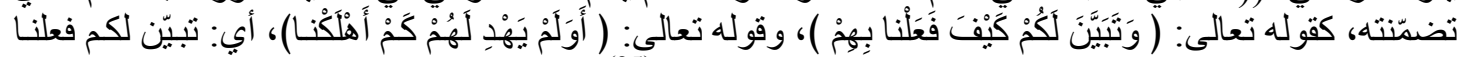

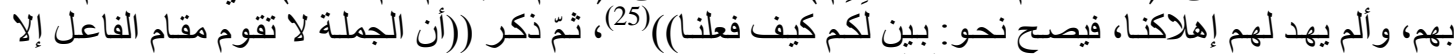

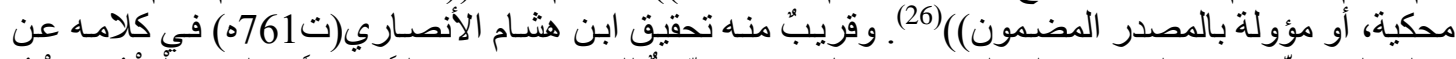

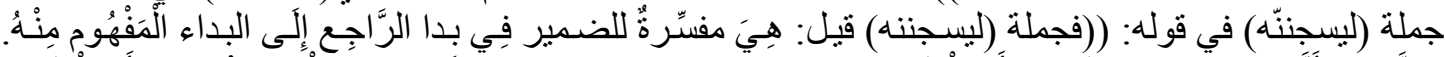

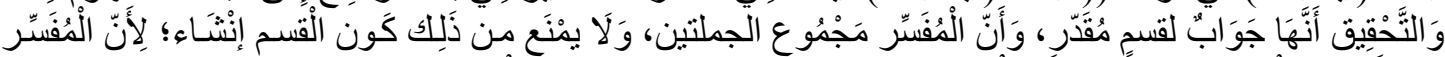

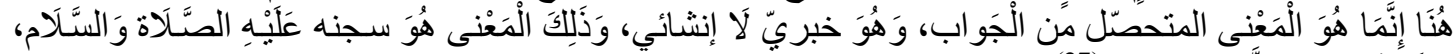

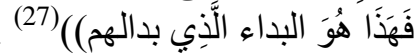

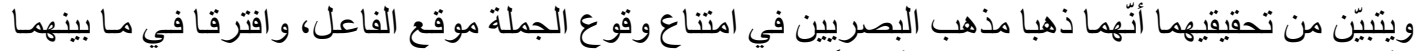

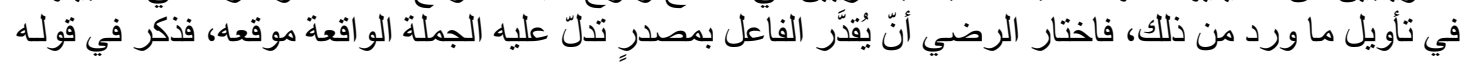


2020 سبتمبر

ISSN: 2415 - 4822
Volume (15)
العدد (15)

September 2020

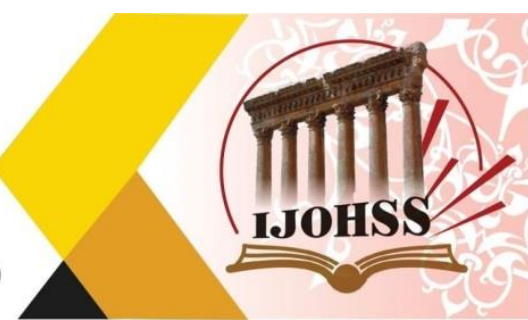

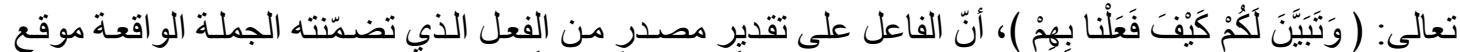

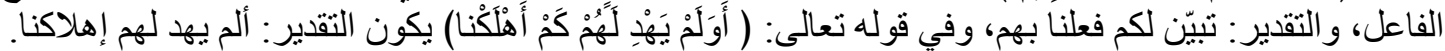

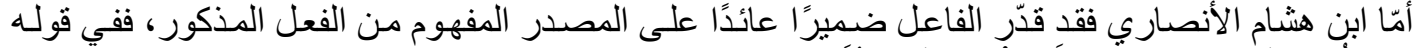

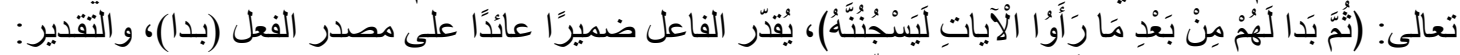

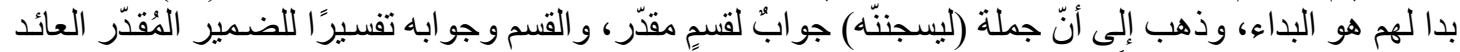

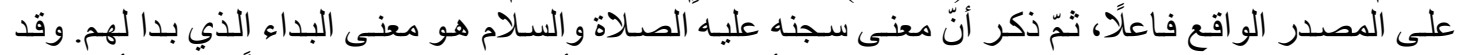

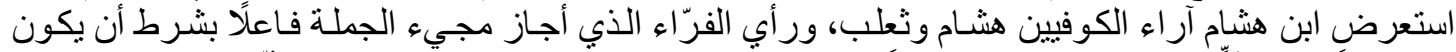

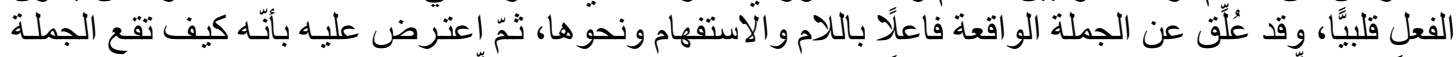

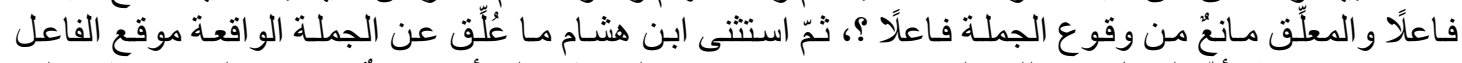

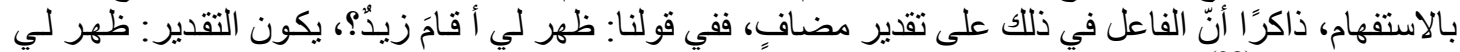

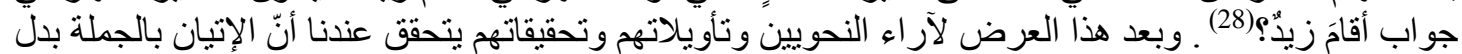

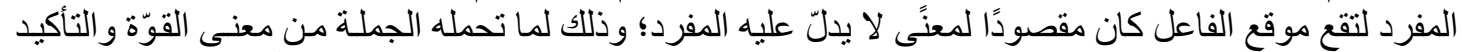

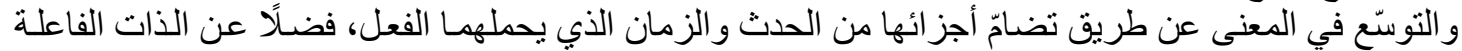

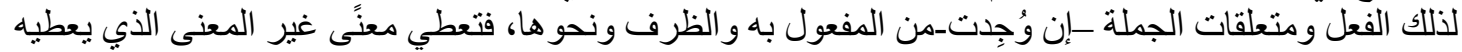

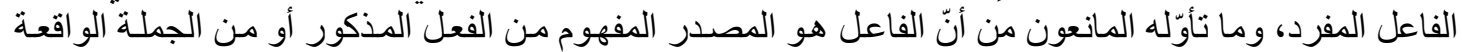

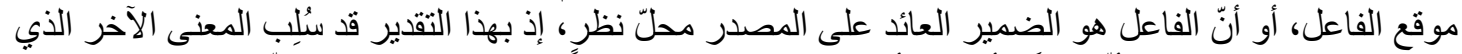

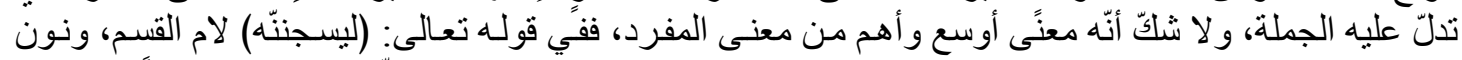

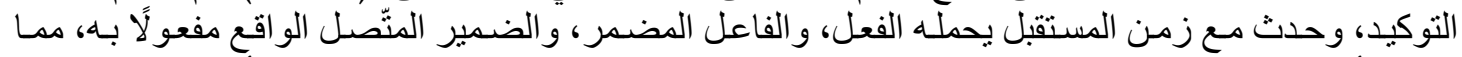

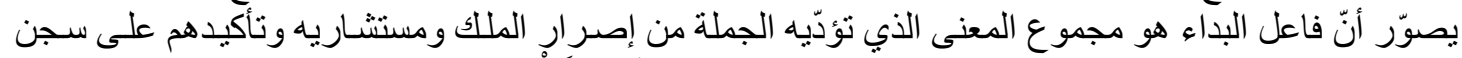

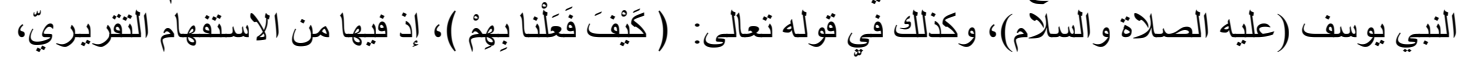

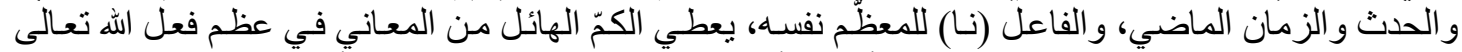

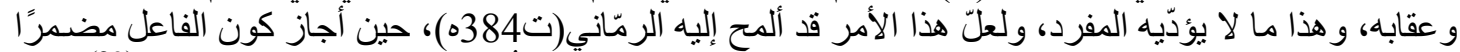

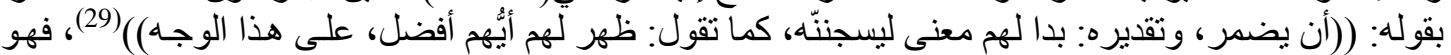

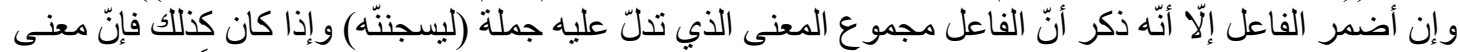

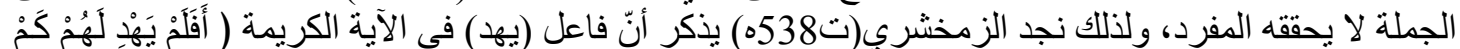

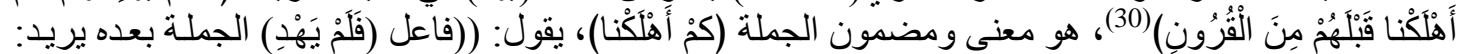

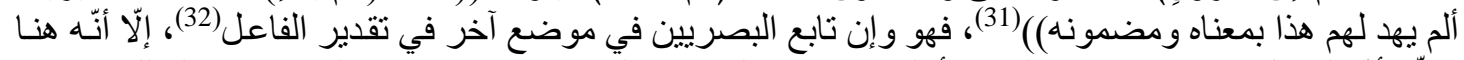

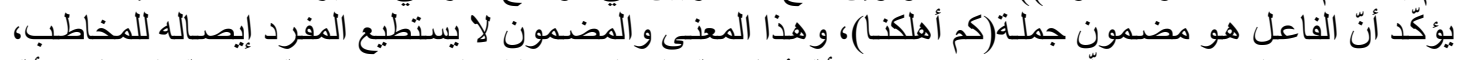

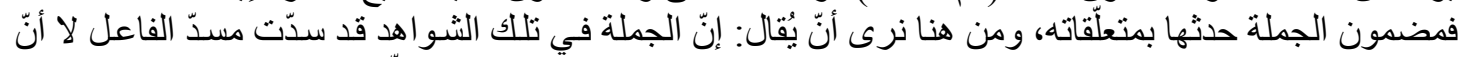

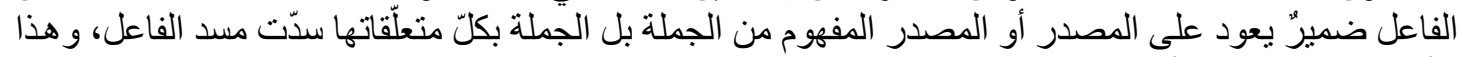

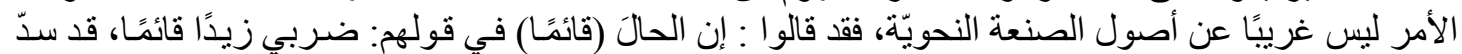

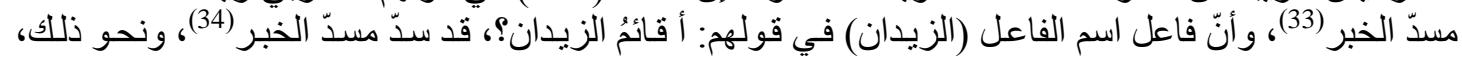

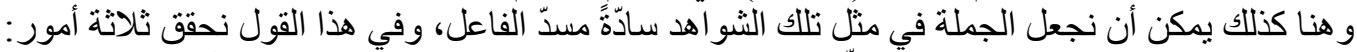

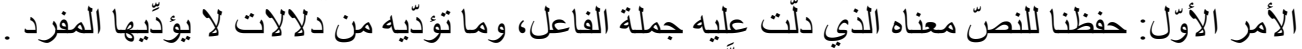

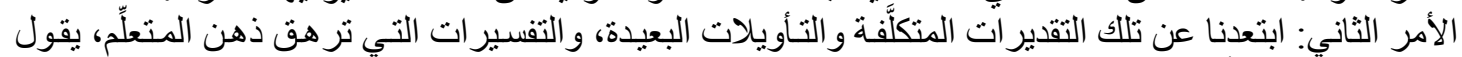

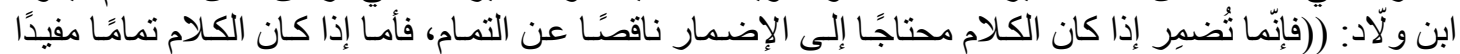

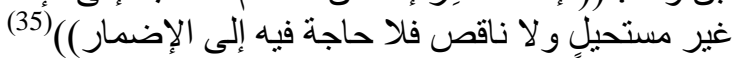

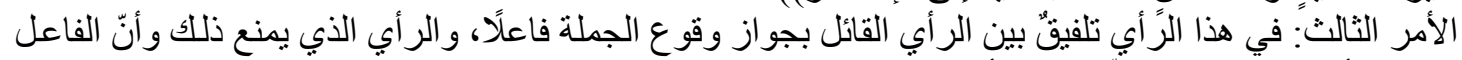

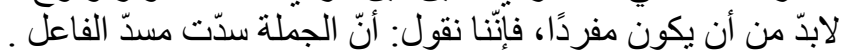

المسألة الثانية: نيابة غير المفعول به مناب الفاعل

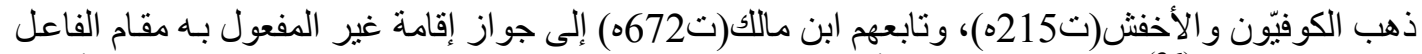

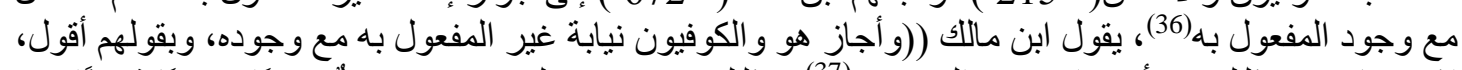

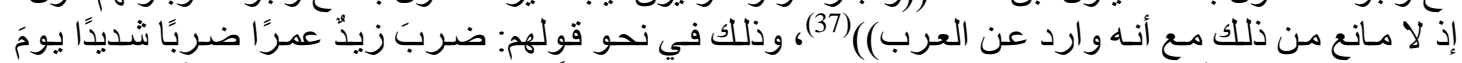

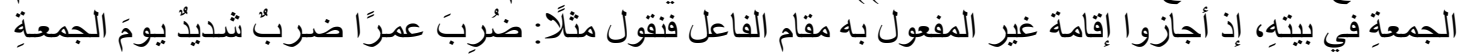




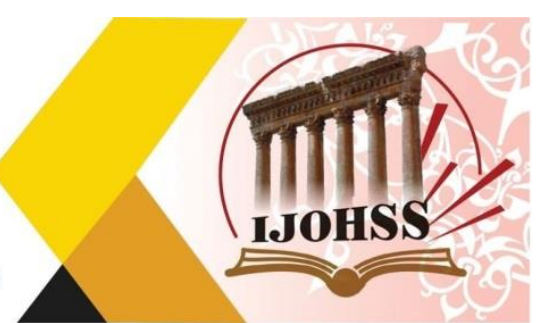

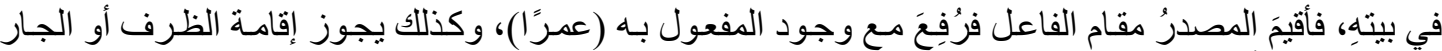

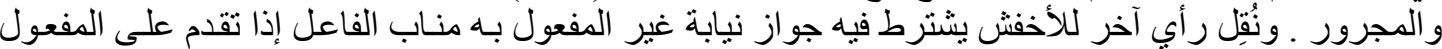

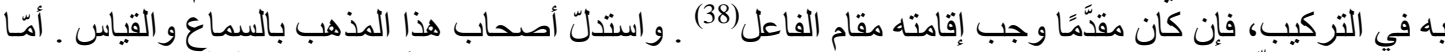

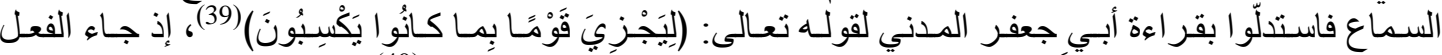

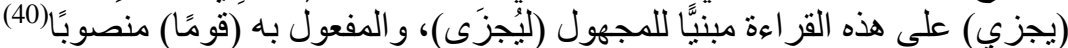

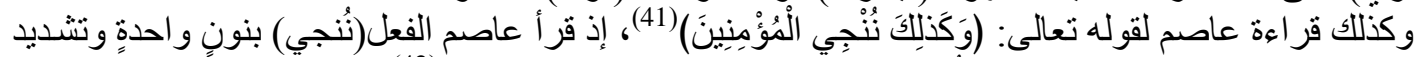

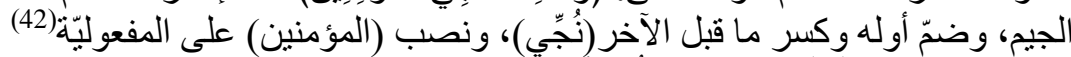

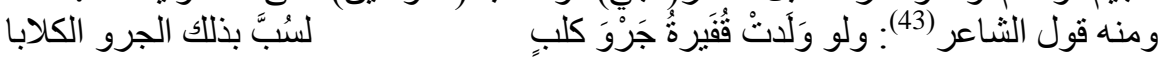

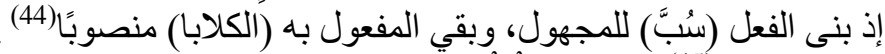

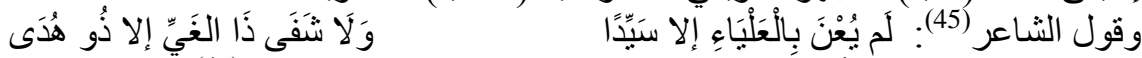

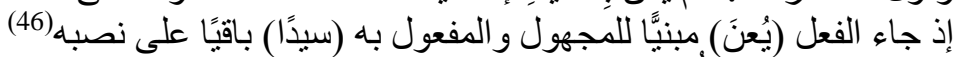

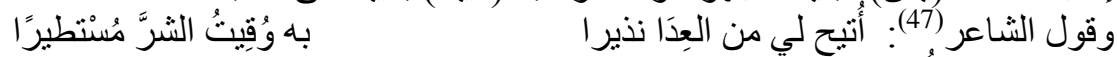

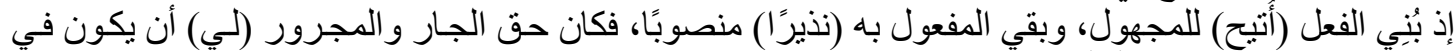

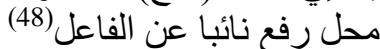

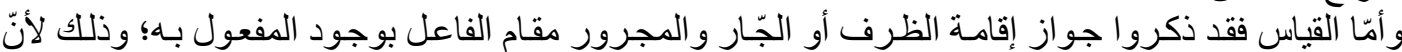

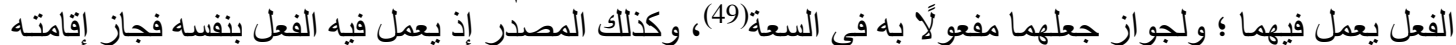

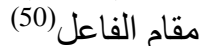

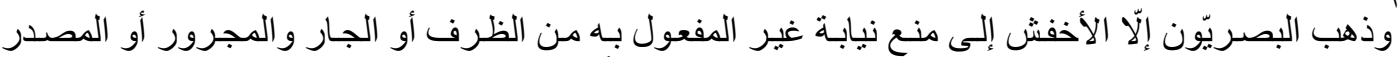

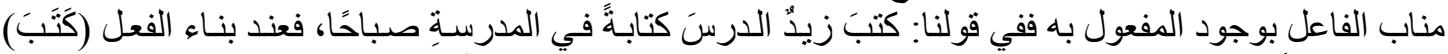

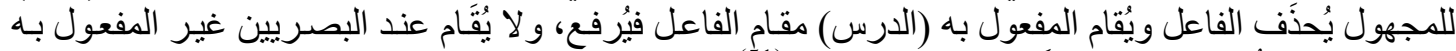

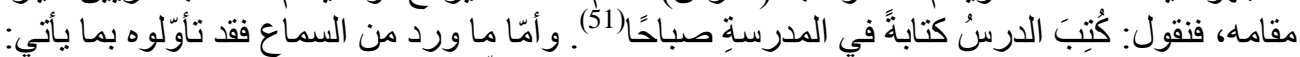

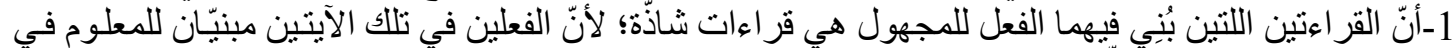

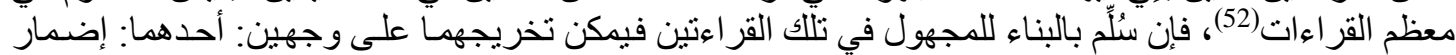

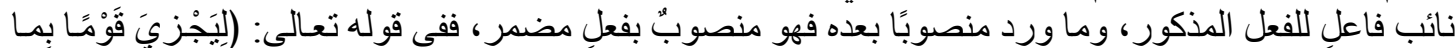

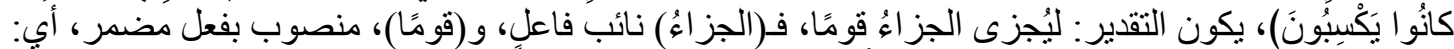

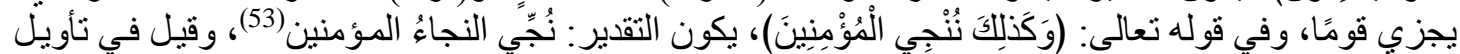

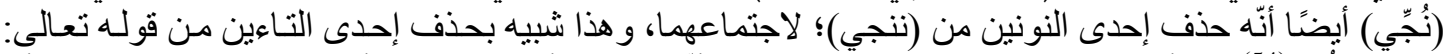

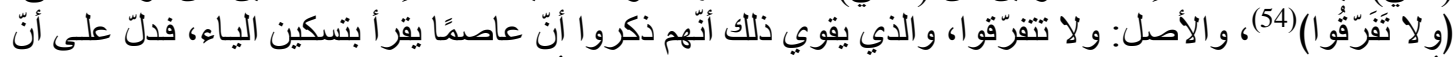

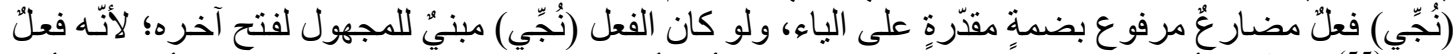

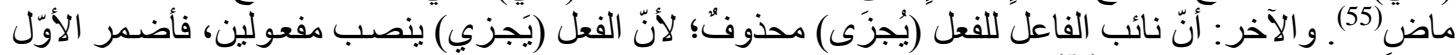

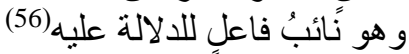

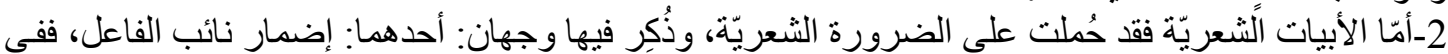

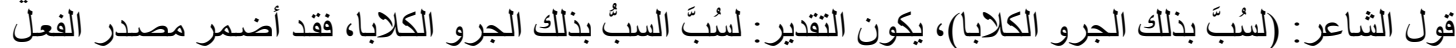

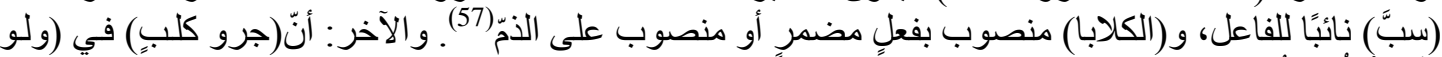

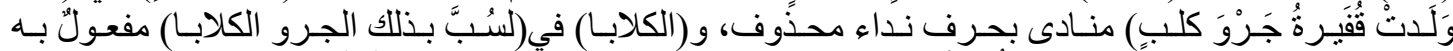

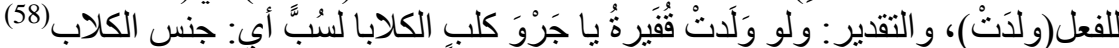

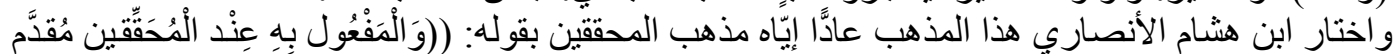

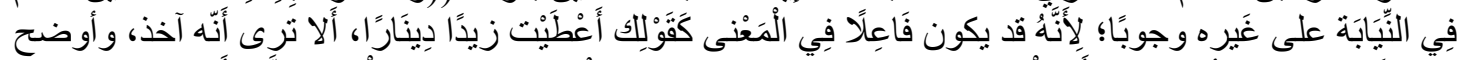

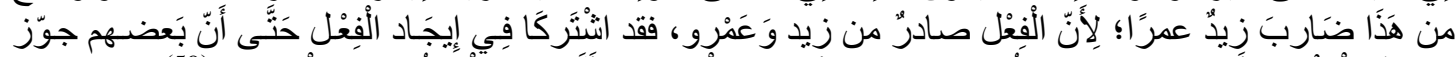

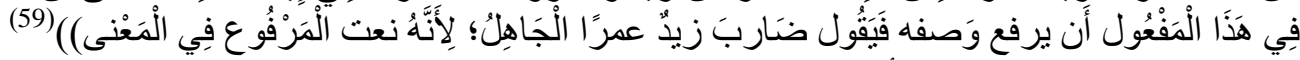

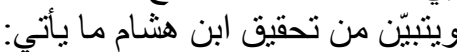

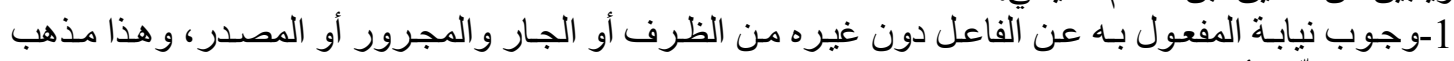
البصريين إلّا الأخفش . المفول

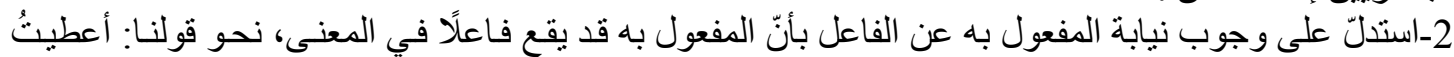

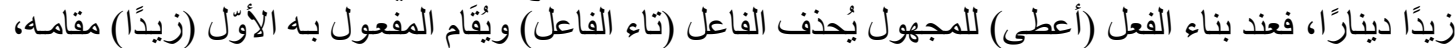


2020 سبتمبر

ISSN: $2415-4822$
العدد (15)

September 2020

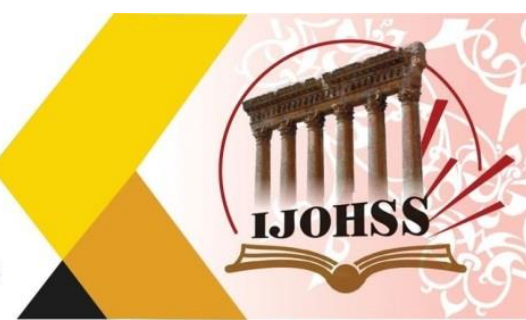

فتقول: أُعطِي زيدٌ دينارًا، وبالتحقيق في هذه الجملة نجد أنّ (زيدٌ) في الأصل فاعل في المعنى؛ لأنّه الآخذ دينارًا

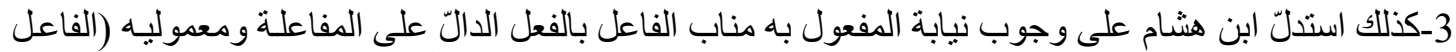

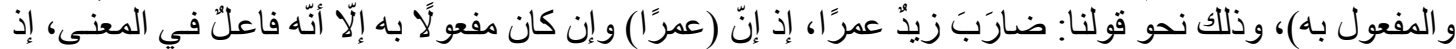

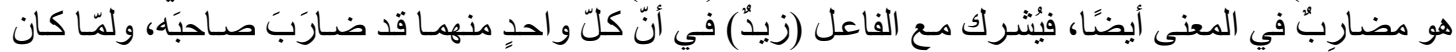

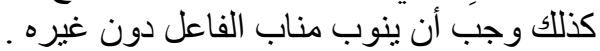

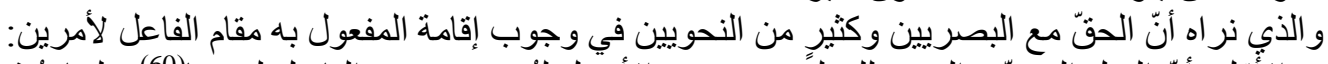

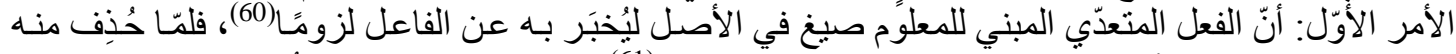

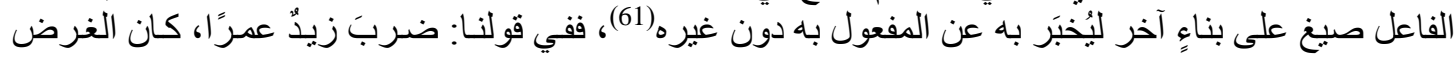

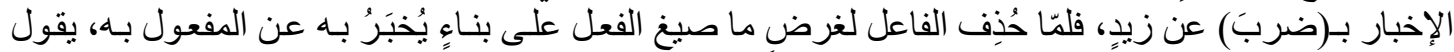

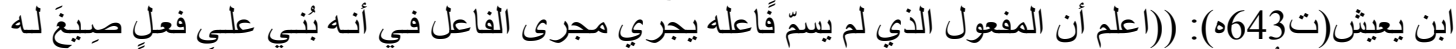

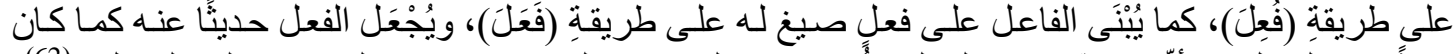

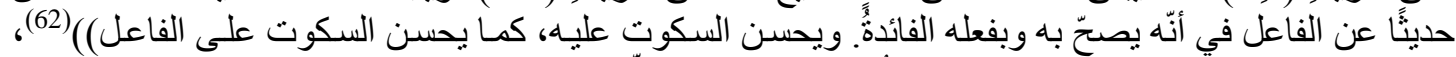

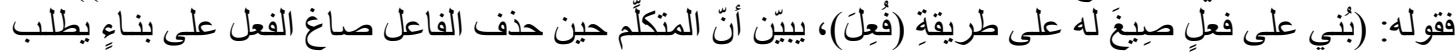

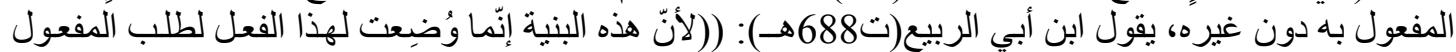

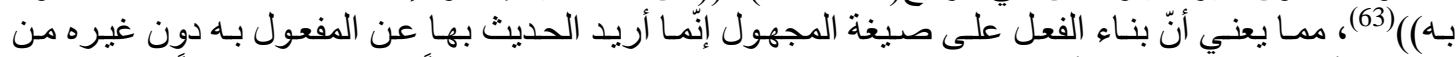

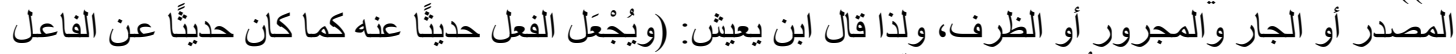

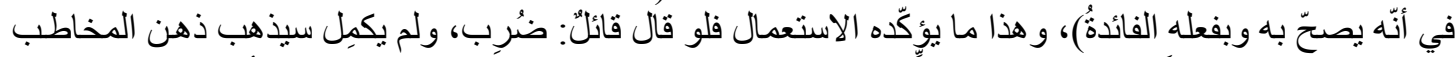

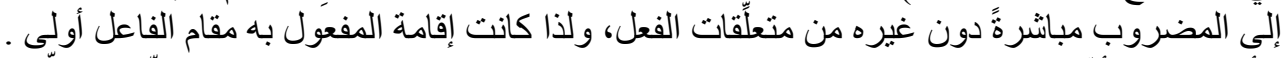

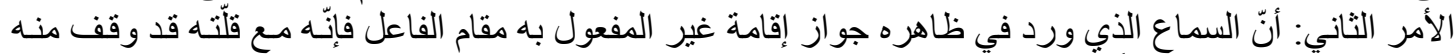

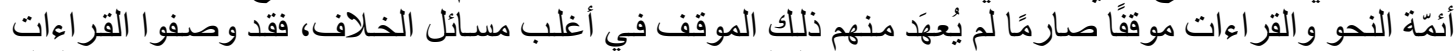

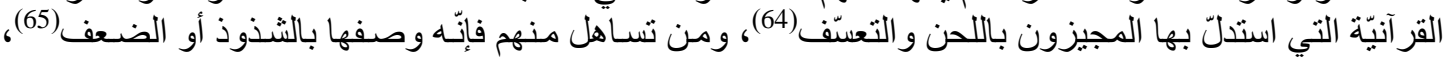

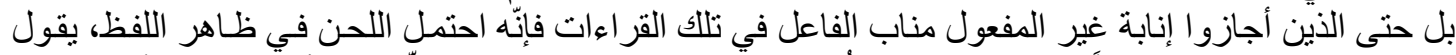

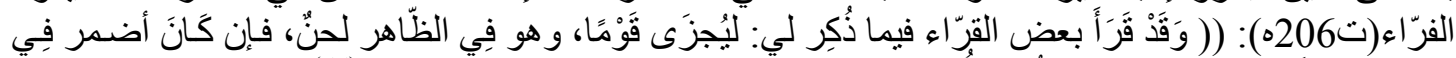

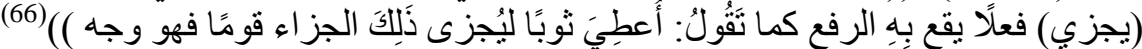

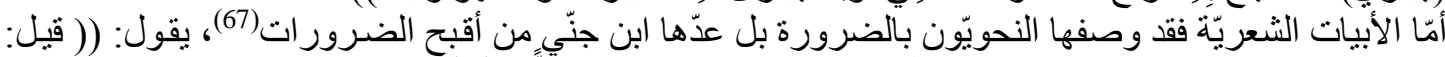

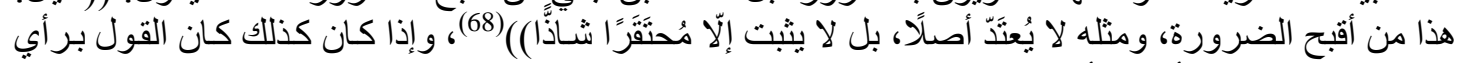
البصريين و المحققين أولى و أصحّ.

المسألة الثالثة: تعدد الحال وصاحبها واحدُ

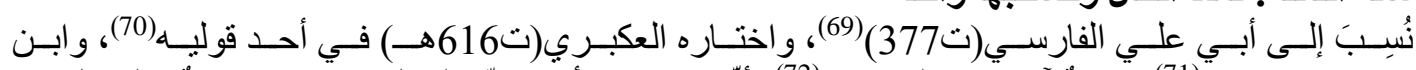

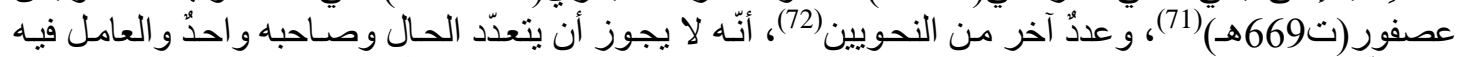

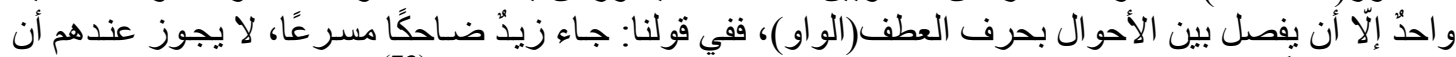

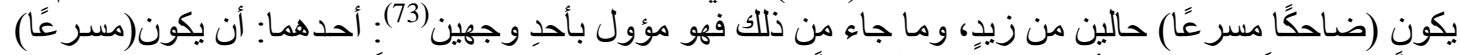

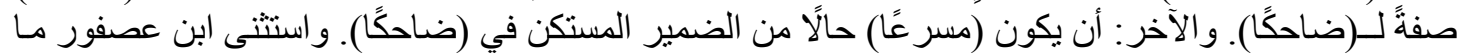

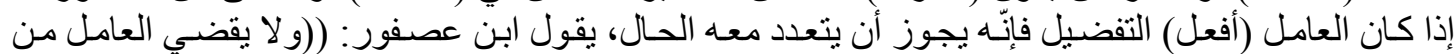

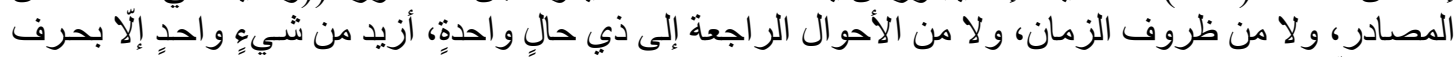

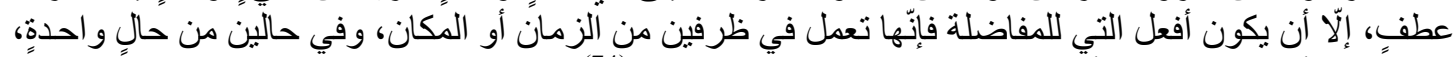

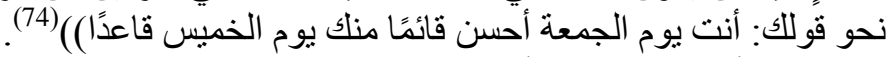

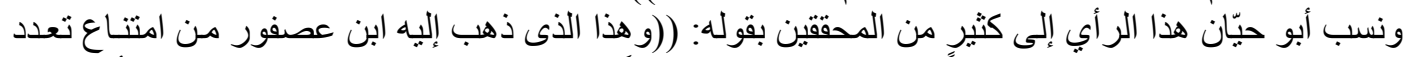

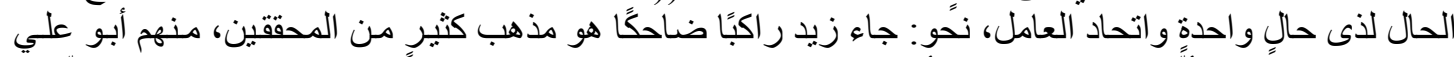

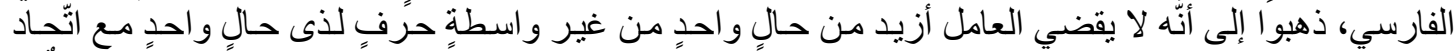

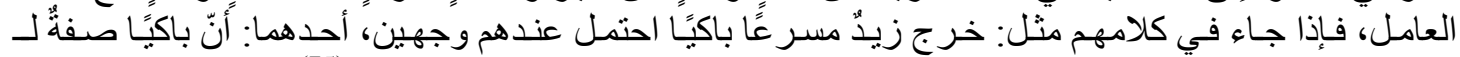

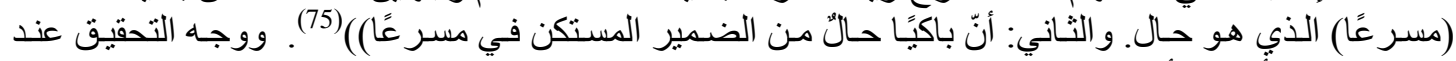

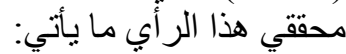


2020 سبتمبر

ISSN: $2415-4822$
Volume (15)
العدد (15)

September 2020

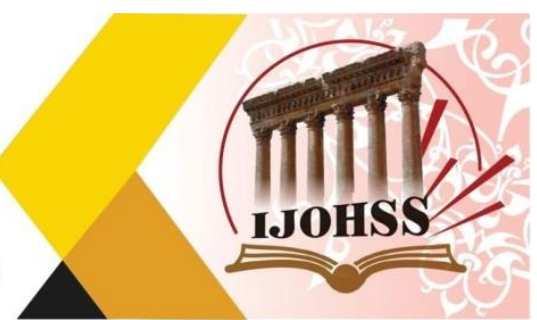

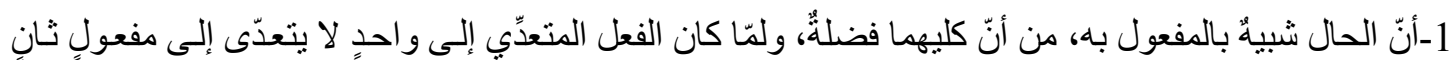

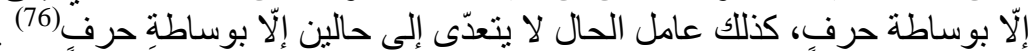

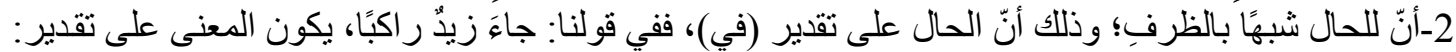

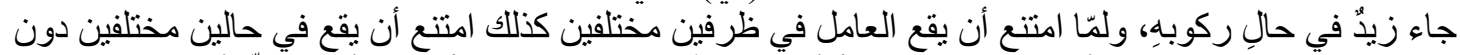

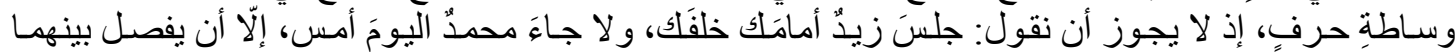
بحرف عطف (77)

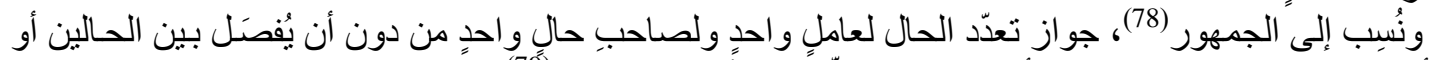

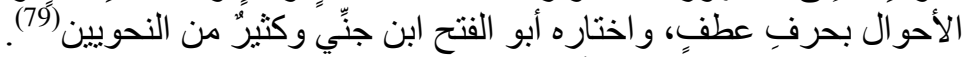

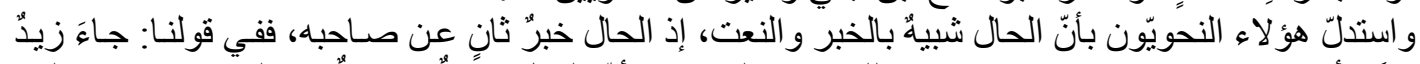

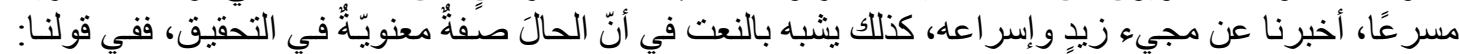

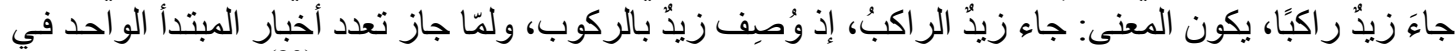

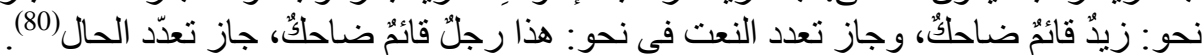

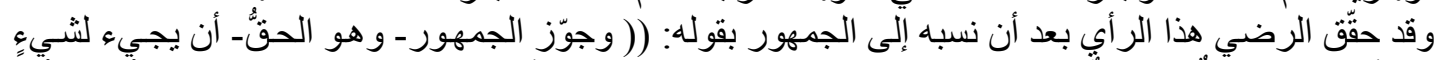

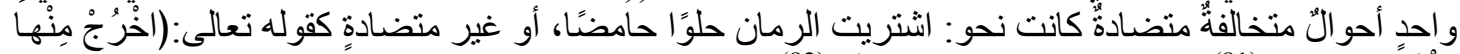

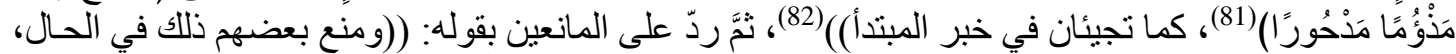

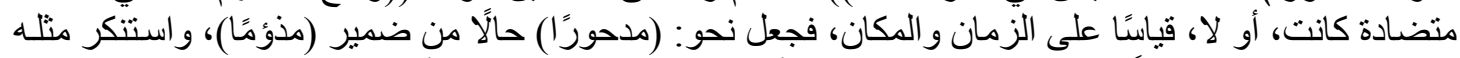

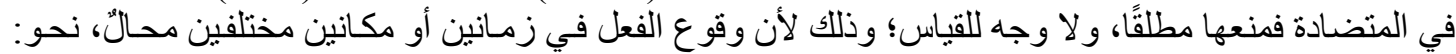

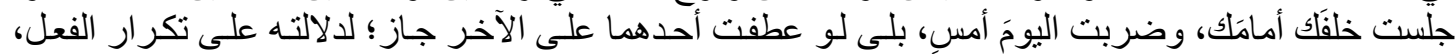

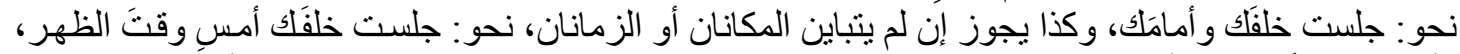

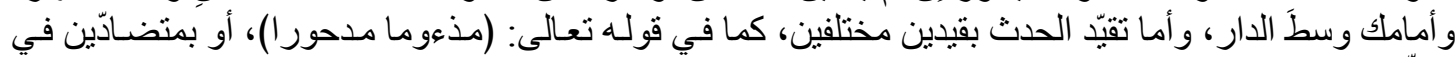

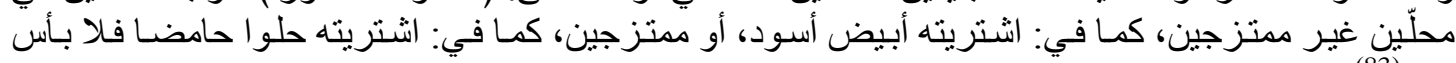
${ }^{(83)}(()$

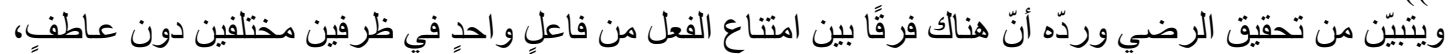

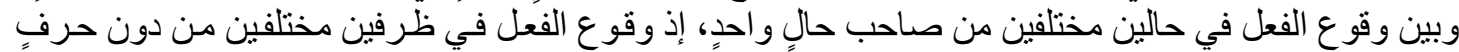

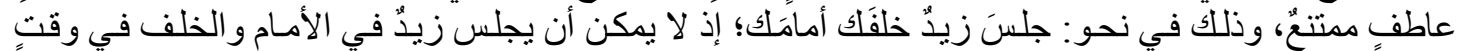

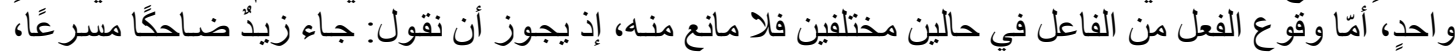

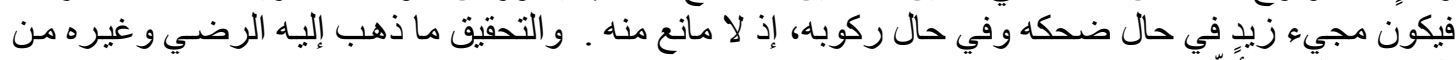
المجيزين الثقلاثة أدلِّة:

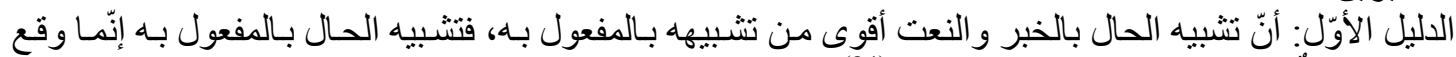

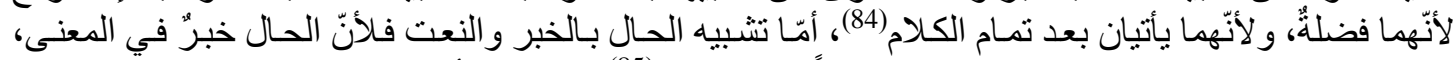

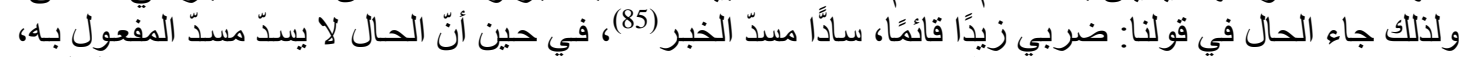

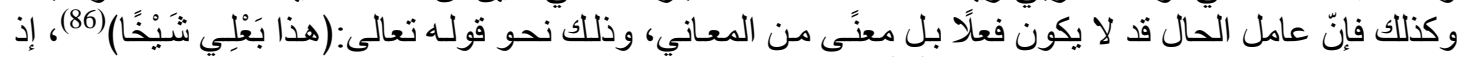

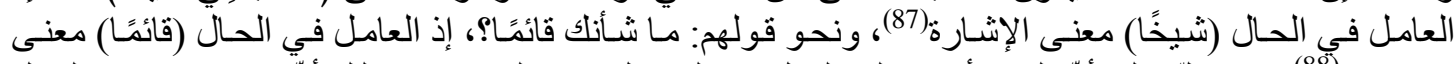

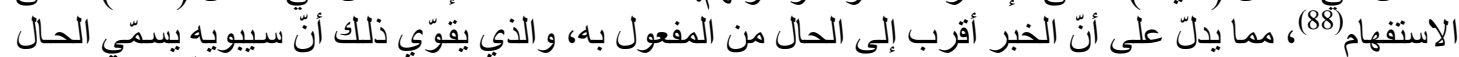

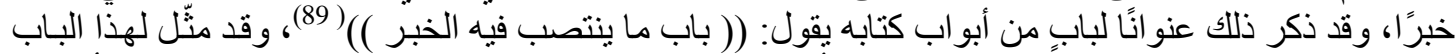

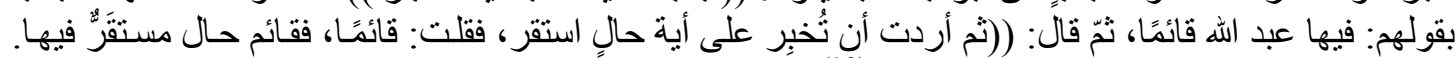

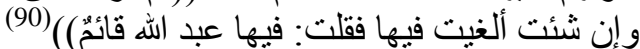

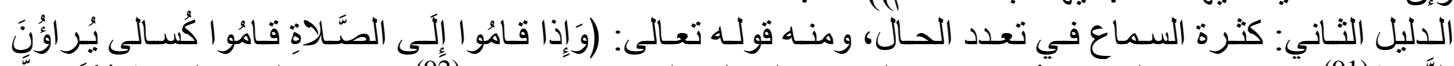

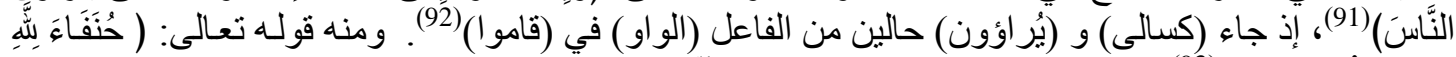

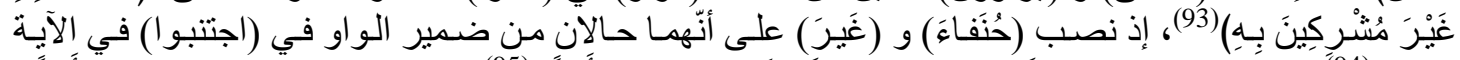

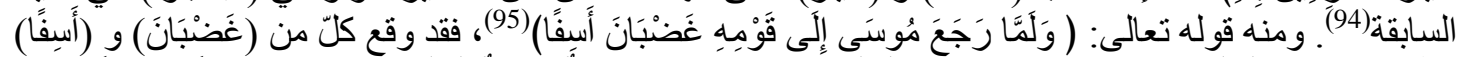

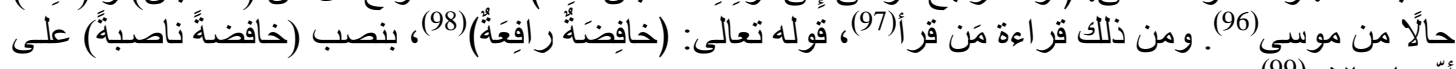

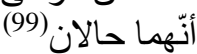

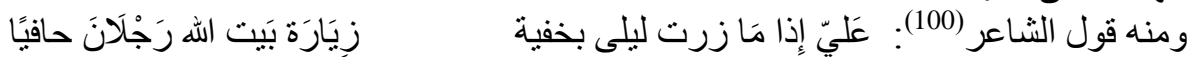

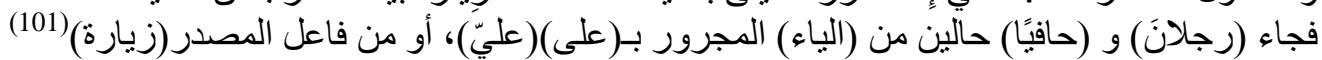


2020 سبتمبر

ISSN: $2415-4822$
Volume (15)
العدد (15)

September 2020

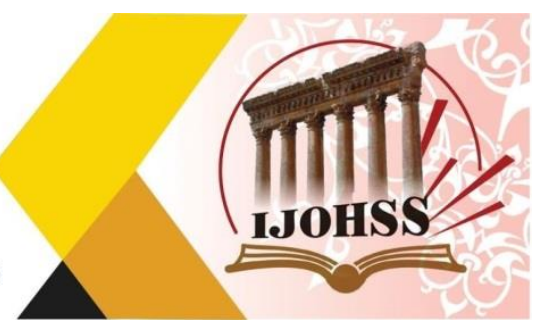

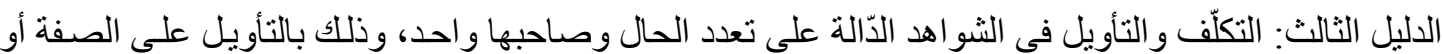

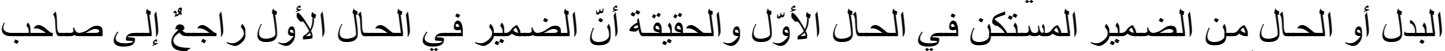

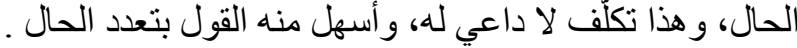

المسألة الرابعة: المعرّف بـ(أل) بعد (يا أيّها)

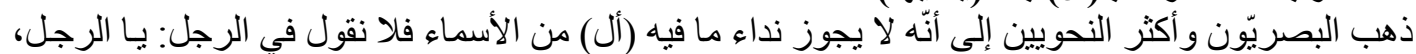

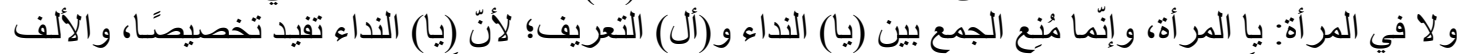

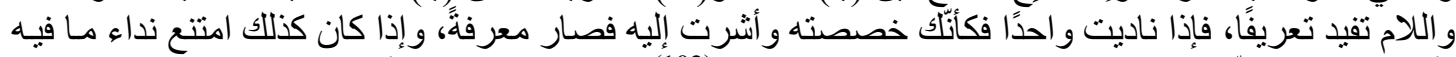

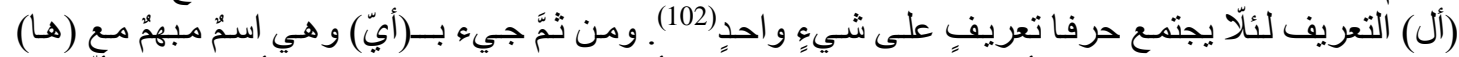

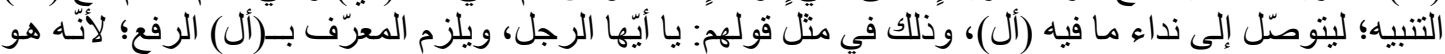

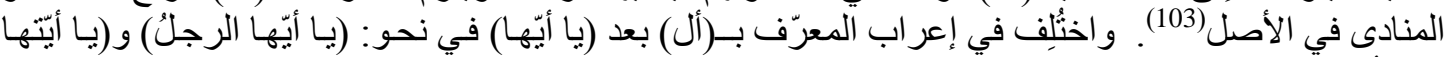

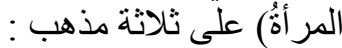

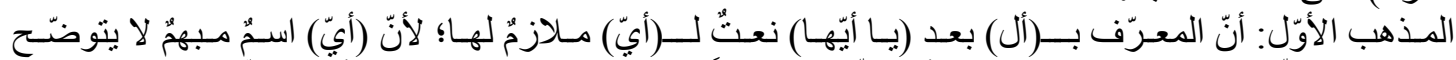

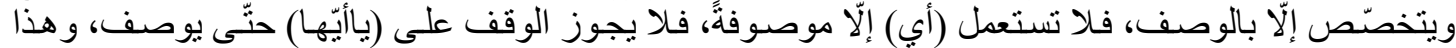

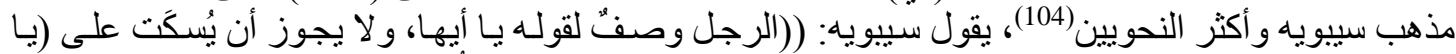

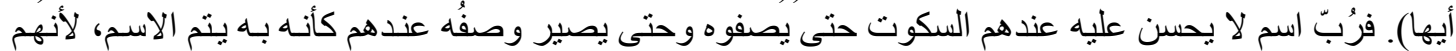

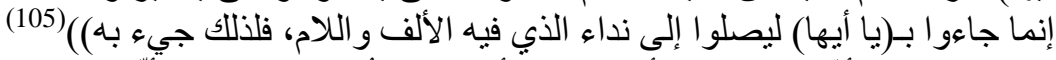

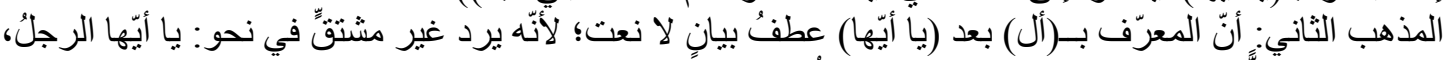

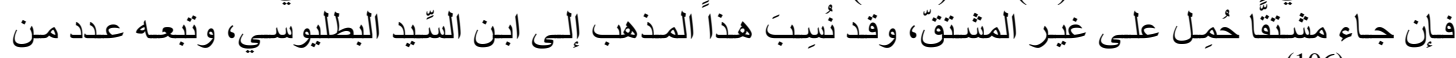
النحويِّن (106) . فئن المذهب الثالث: أنّ المعرّف بــ(أل) بعد (يـا أيّها) يُعرَب نعنًا إذا كان مشتقَّا، و عطف بيانٍ إذا كان جامدًا، و هذا

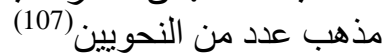

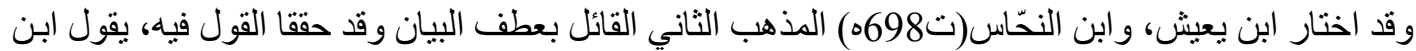

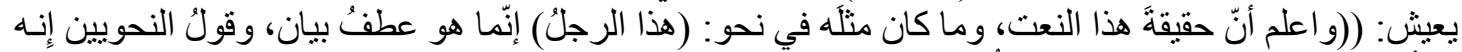

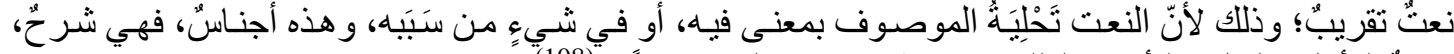

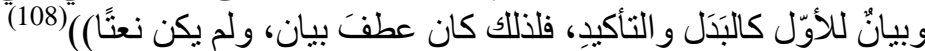

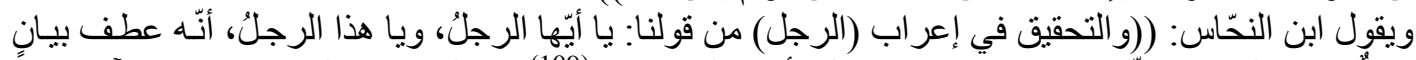

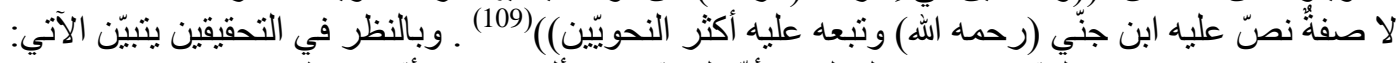

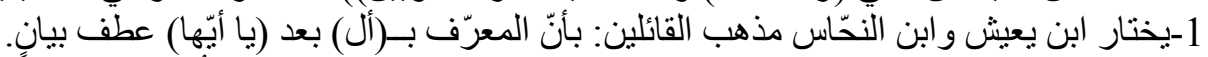

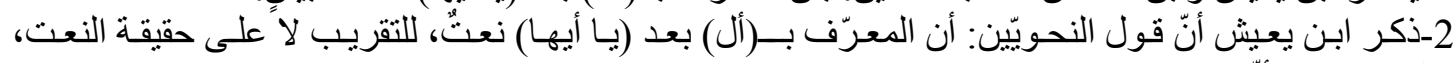

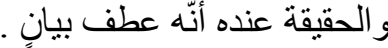

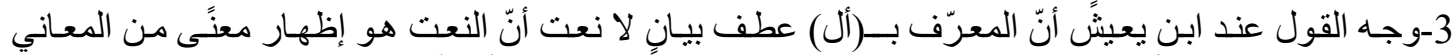

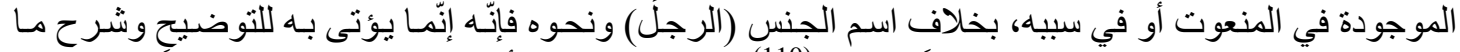

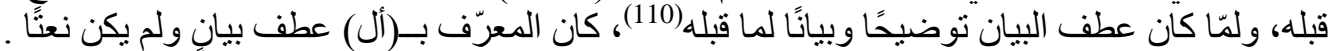

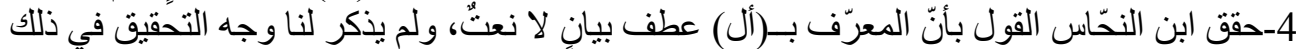

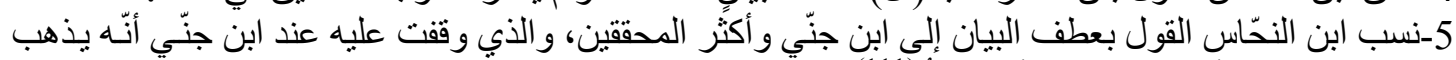

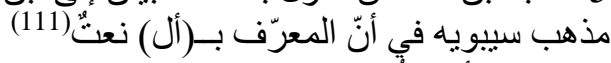

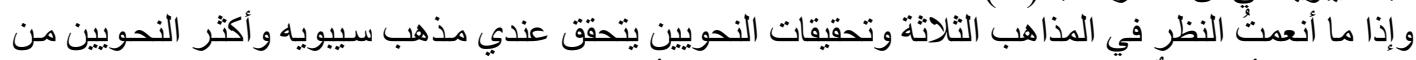

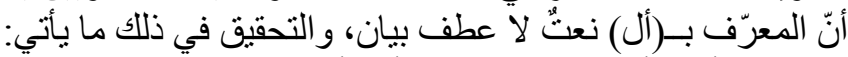

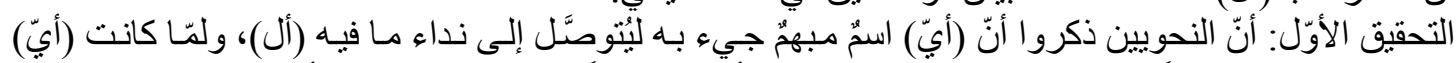

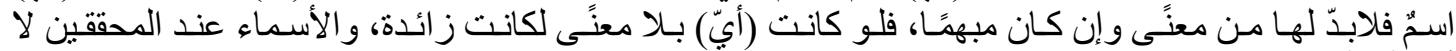

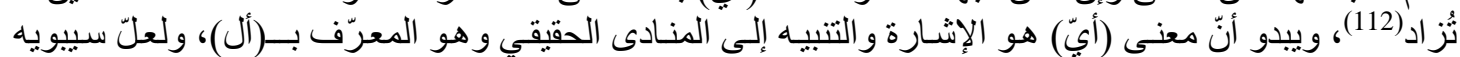

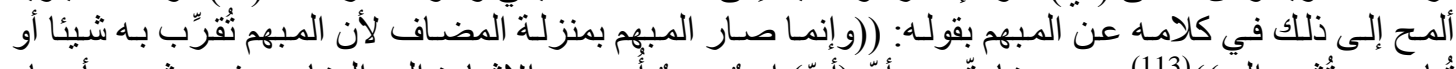

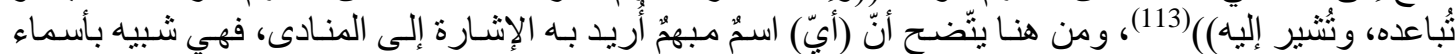

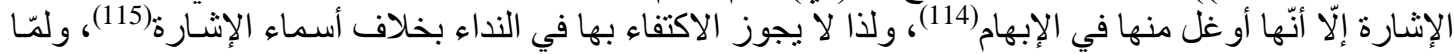




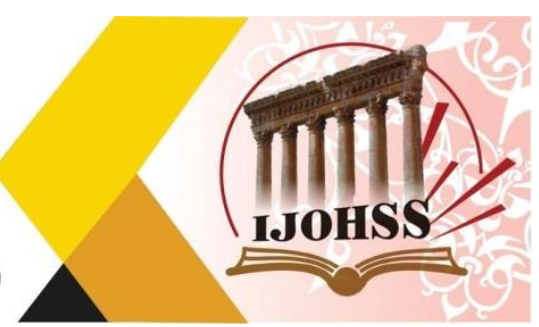

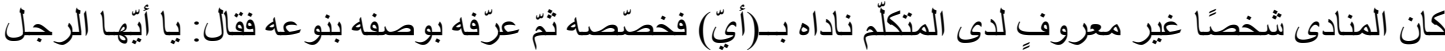

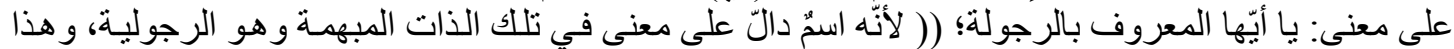

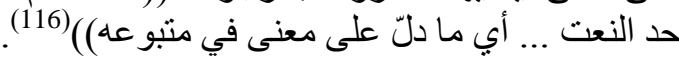

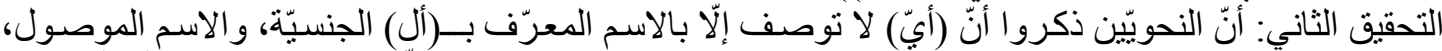

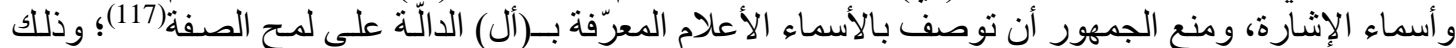

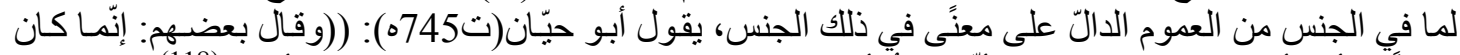

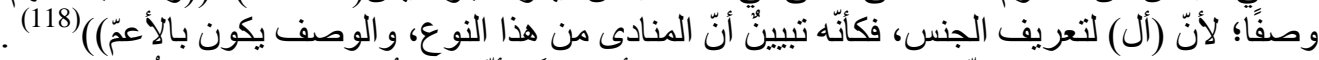

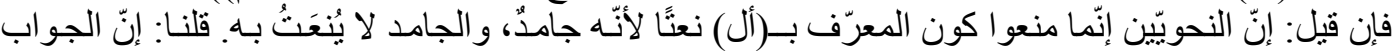

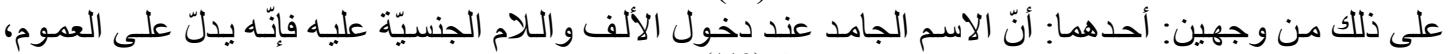

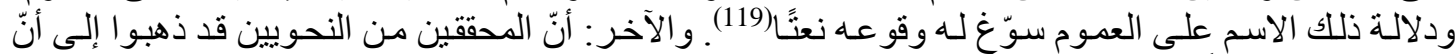

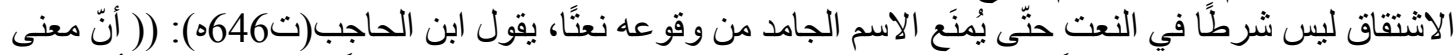

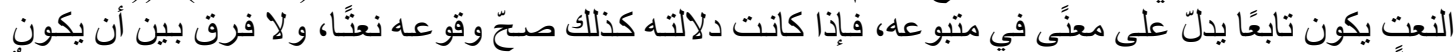

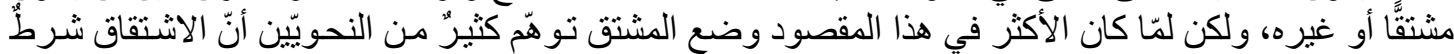

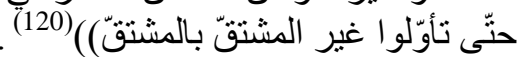

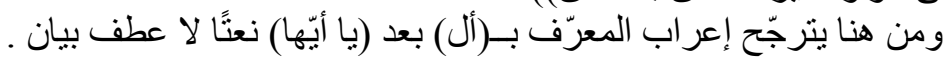

المسألة الخامسة: المعطوف على معمول اسم الفاعل

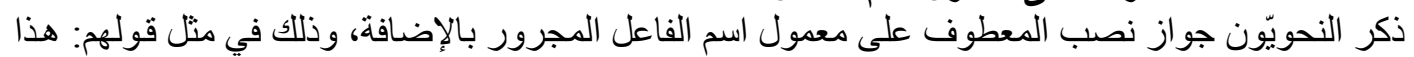

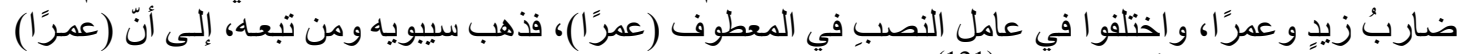

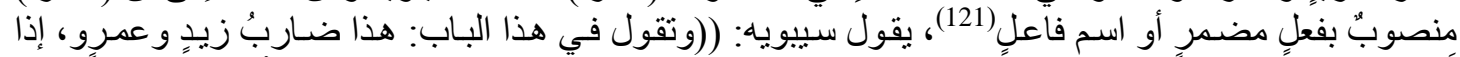

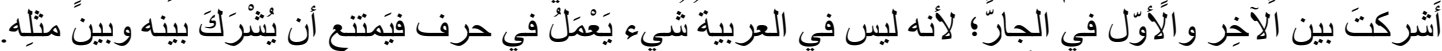

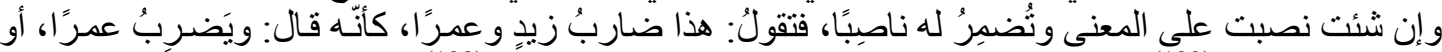

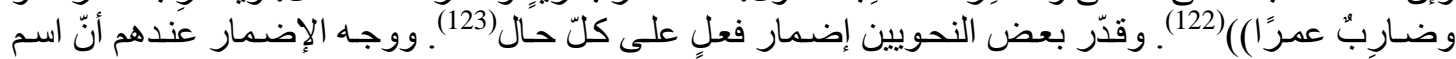

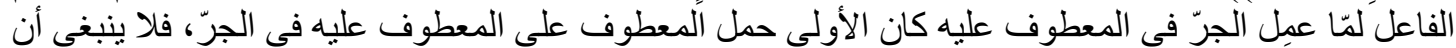

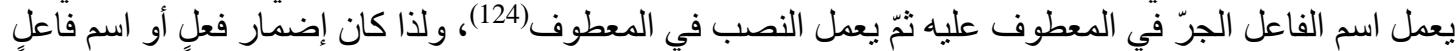

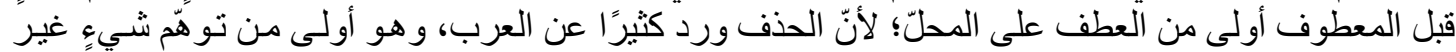

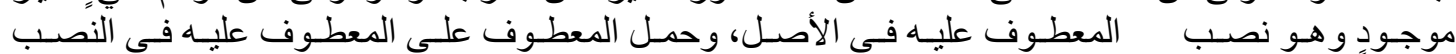

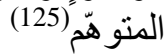

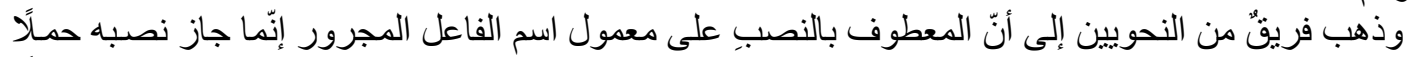

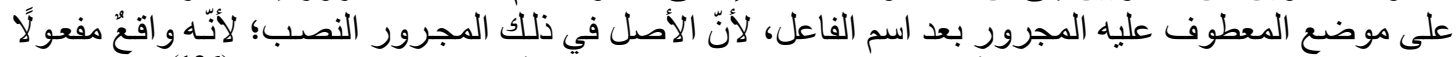

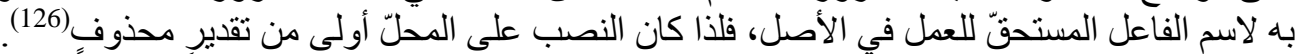

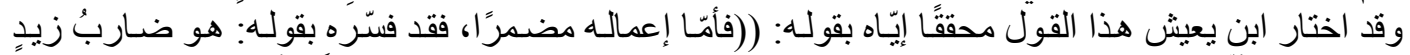

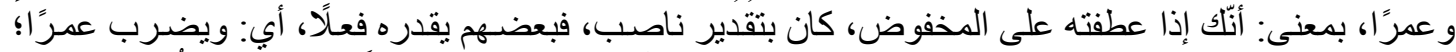

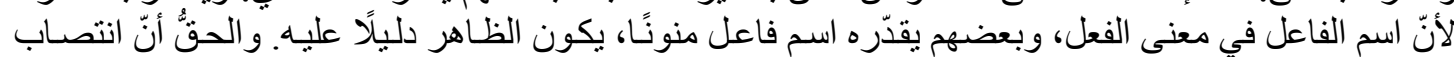

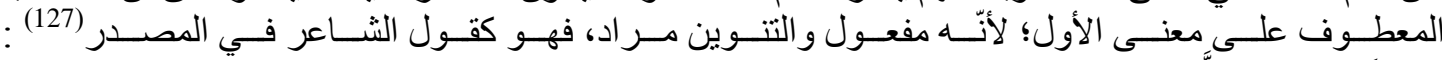
مَخافةً الإفلاس و اللَّبَّانا

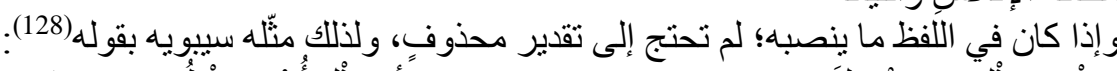

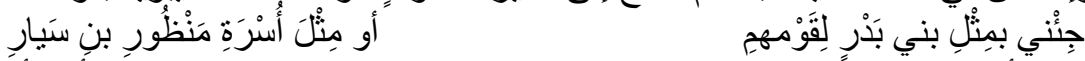

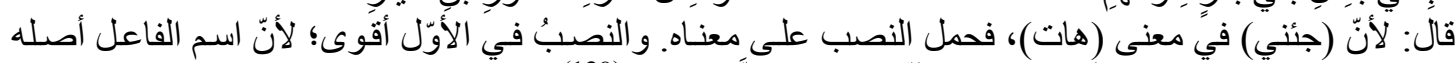

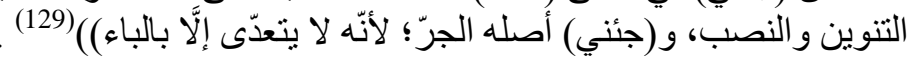

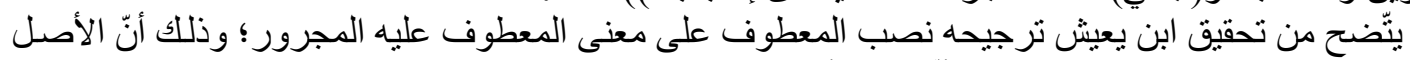

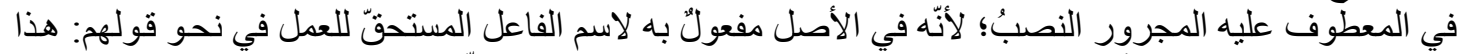

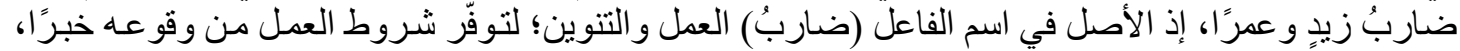

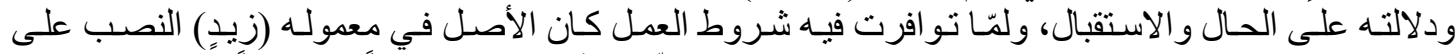

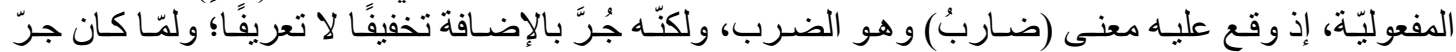




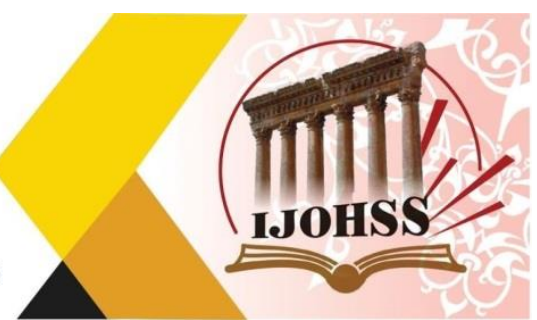

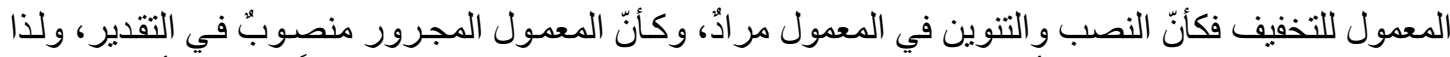

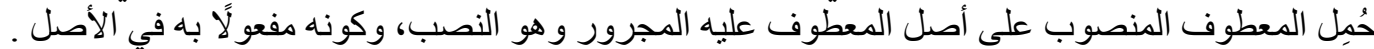

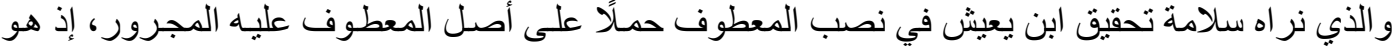

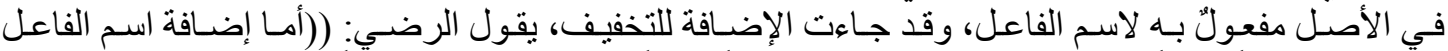

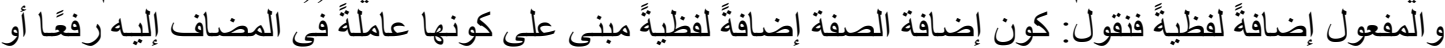

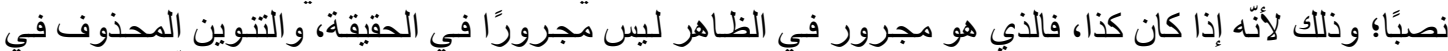

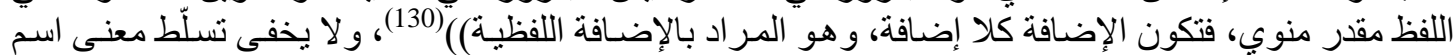

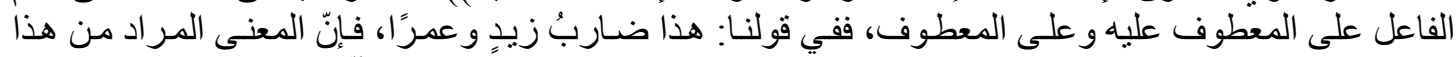

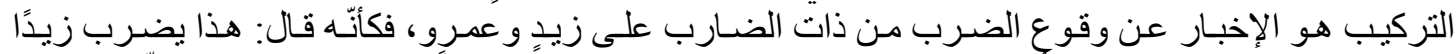

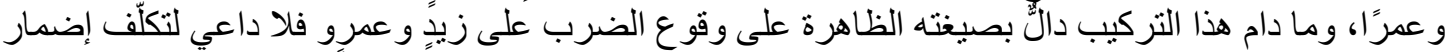

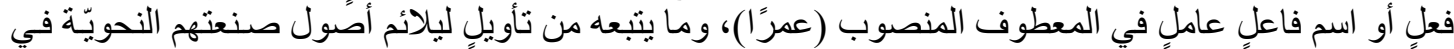

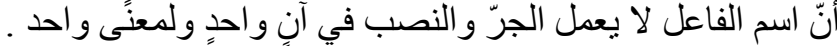

الخاتمة

أهم النتائج التي خلُص إليها البحث:

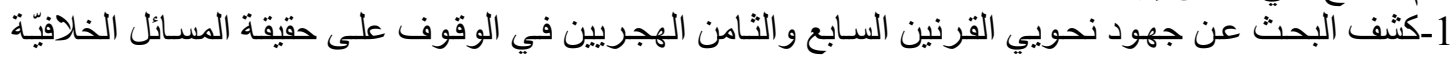

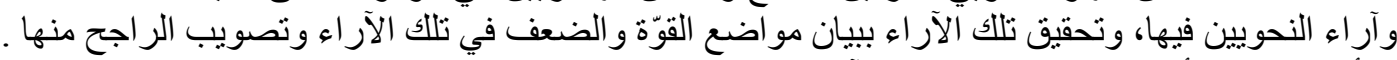

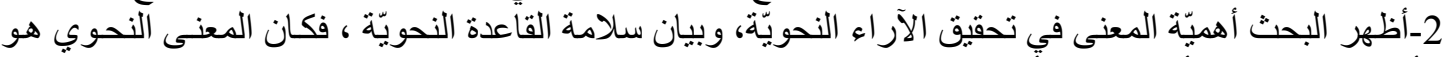

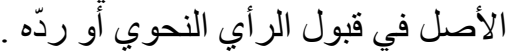

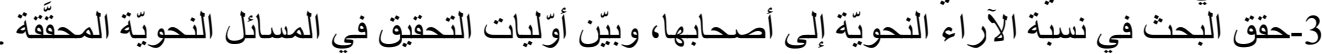

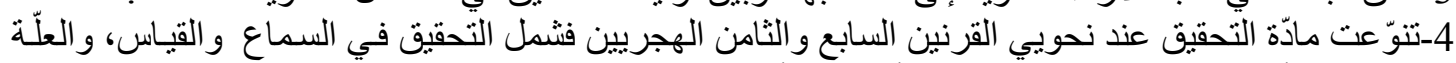

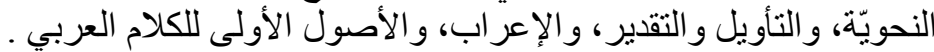

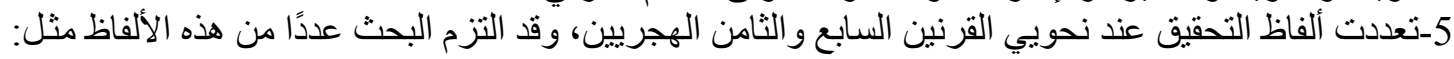

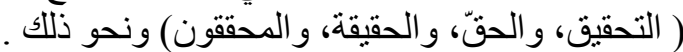

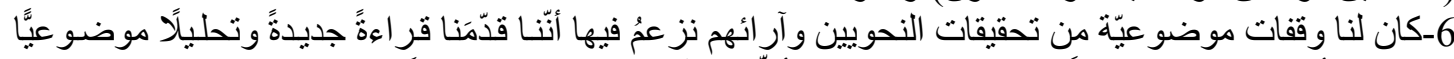

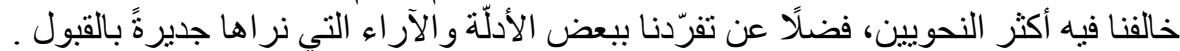

النهوامش

1- ينظر: التذييل و التكميل: 56/1، ومغني اللبيب: 524، و المقاصد الثافية: 238/2 ـ

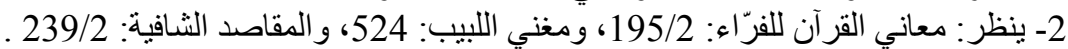

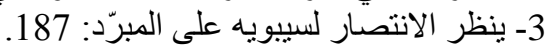
4- ينظر : إعر اب القرآن للنحاس: 202/2-203، و التذييل و التكميل: 56/1، وهمع الهو امع: 590/1 .

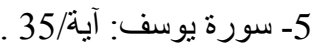
6- ينظر : التذييل و التكميل: 54/1، وشرح شـذ شذور الذهب: 217 ـ

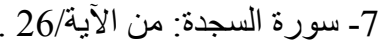

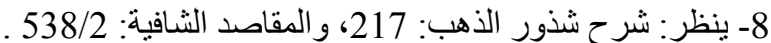

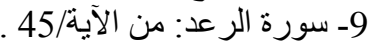

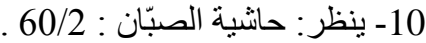
11 - 12 ديو انه: 639

12 - 12 بنظر : المقاصد الثنافية: 539

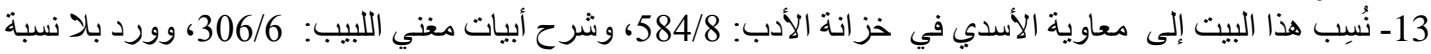
في الحجة للقرّاء السبعة: 156/4-157، و الخصائص: 436/2، وشرح المفصل: 5/3، وشرح التسهيل: 50/4، و التذييل و ألتكميل: 14 - ينظر: مغني اللبيب: 559 : 559

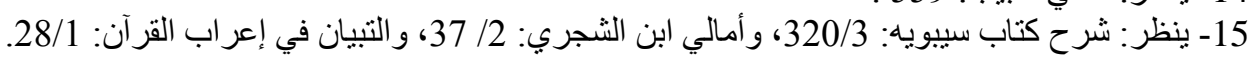


2020 سبتمبر

ISSN: $2415-4822$
Volume (15)
العدد (15)

September 2020

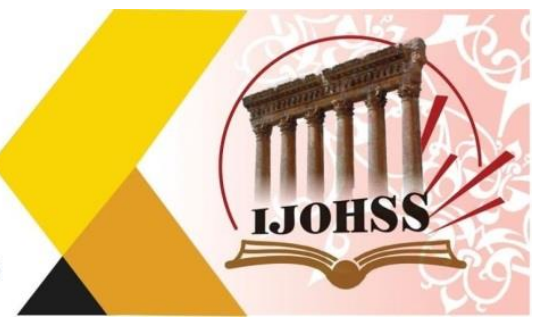

16- ينظر : المسائل البغداديّات: 368 ـ 368 ـ 17 - 16 ينظر : أمالي ابن الحاجب:

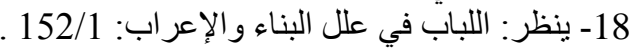

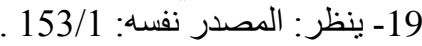

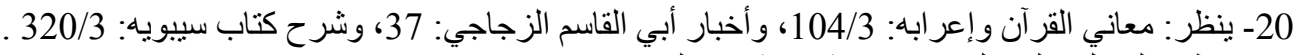

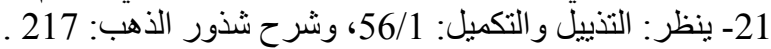

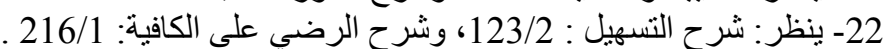

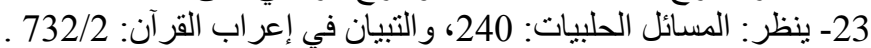

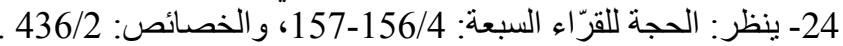

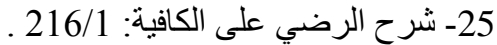

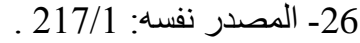
27- 27 - مغني اللبيب: 523 ـ 523

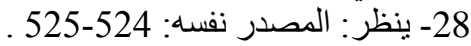
29 - شرح كتاب سييو يه: 1073 ـ 1072

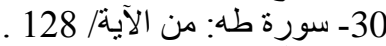

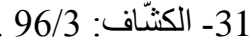

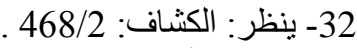

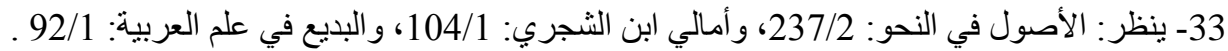

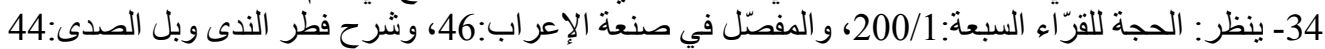

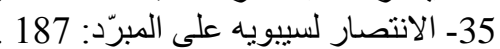

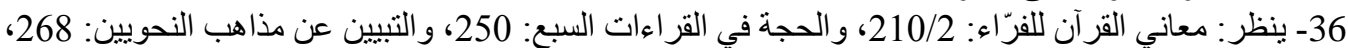

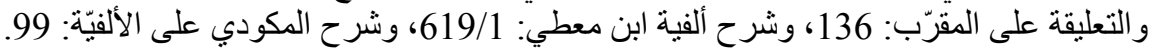

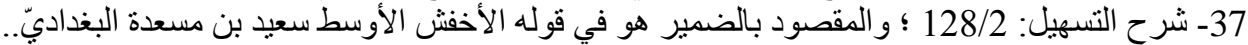

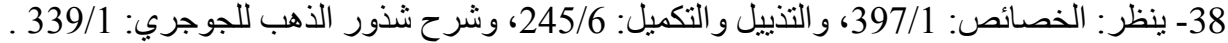
39 - 3و سورة الجاثية: من الآية/14 40ـ بنظر : تأويل مشكل القرآن: 41، و المبسوط في القراءات العشر: 403، و إتحاف فضلاء البشر في القراءات الأربعة

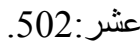

4 - 41 سورة الأنبياء: من الآية / 88 ـ 88.

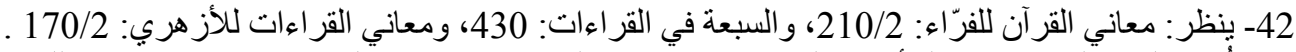

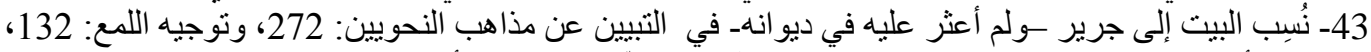

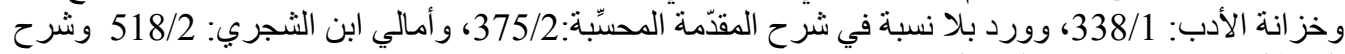
المفصّل: 314/4، وشر ح التسهيل: 128/2.

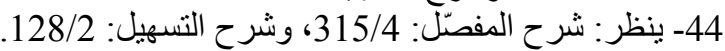

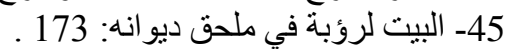

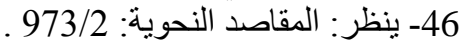

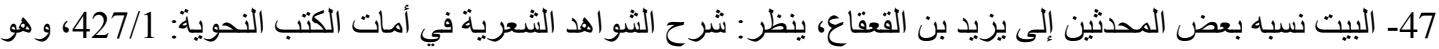
بلا نسبة في شر ح التسهيل: 128/2، و التذييل و التكميل: 244/2، وشر ح شذور الذهب: 212 و 212

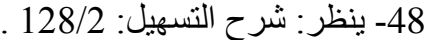

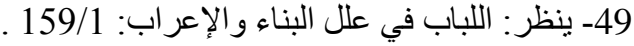

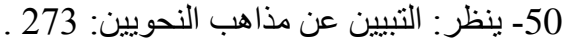
51- ينظر: المقتضب: 51/4، والأصول في النحو: 79/1، والبديع في علم العربيّة: 116/1، و التبيين عن مذاهب النحويين: 268، وشرح المقدّمة الكفية في علم الإعر اب:

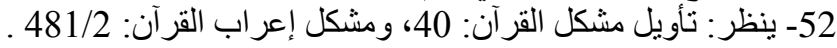

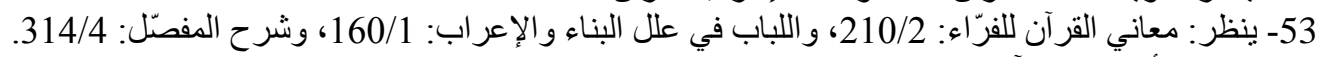

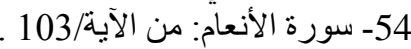
55- ينظر: إعر اب القر آن للنحاس: 56/3، و المحتسب في تبيين وجوه شواء الإ القر اءات و الإيضاح عنها: 1611/2.

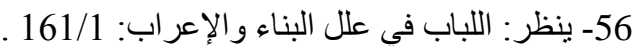
57- ينظر: التعليقة على المقرّب: 137، والتنئيل و والتكميل: 247/6. 
2020 سبتمبر

ISSN: $2415-4822$
Volume (15)

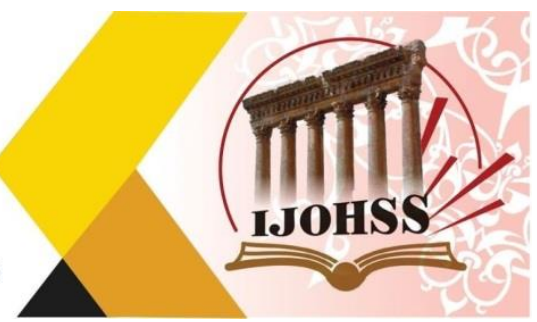

58- ينظر : التبيين عن مذاهب النحويين: 273، وشرح المفصّل: 315/4 ـ .

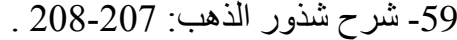

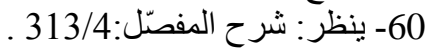
61 61 ينظر: المصدر نفسه: 313/4، و والبسيط في شرح جمل الزجاجي: 960 ـ .

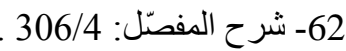

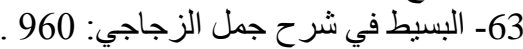

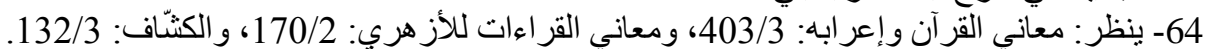

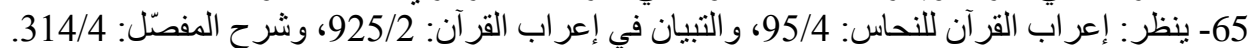

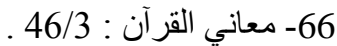

67- ينظر: الحجة للقر اء السبعة: 260/5، و التبيين عن مذا هب النحويين: 273، و التذييل و التكميل: 246/6 ـ

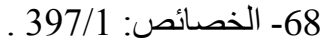

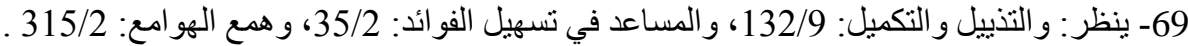
70- ينظر : التبيان في إعر اب القرآن: 31/1 ـ وفي اللباب في علل البناء و الإعر اب: 292/1، أجاز النيّ مجيء حالين لعاملٍ

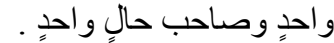

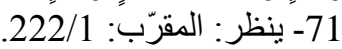

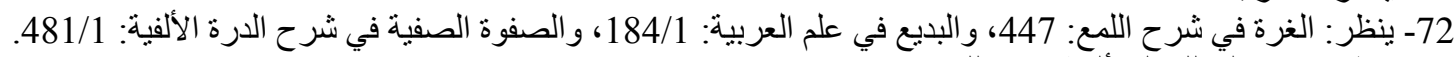

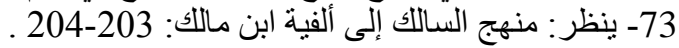
74 - 74 - 73 المقرّب: 222/1.

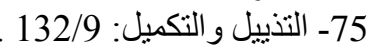

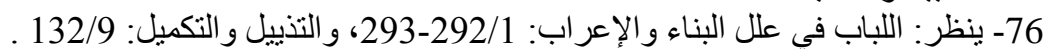

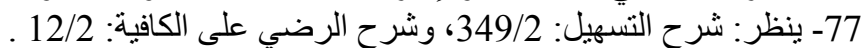

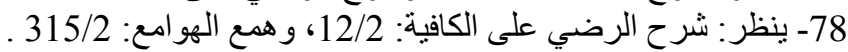

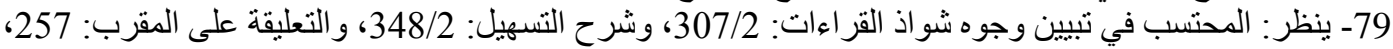

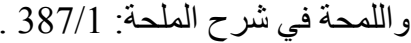

80- ينظر: شروط الحال و أحكامها و أقسامها لابن بري: 6901-690، وشر ح المفصّل: 6/2، وشرح حالتسهيل: 323/2،

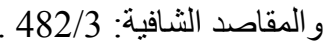

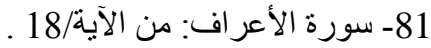

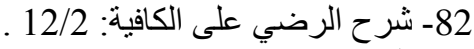

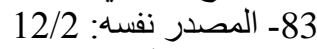

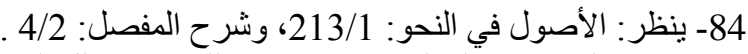

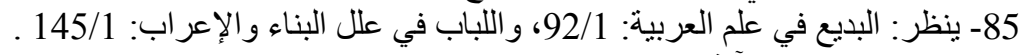

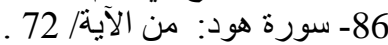

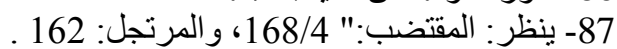

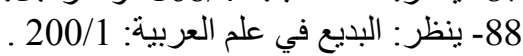

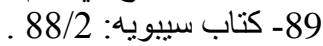

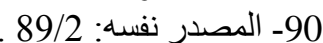
91 91 سورة النساء: من الآية/ 142 ـ 149

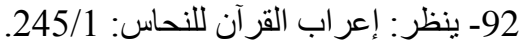

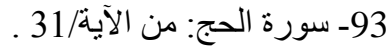
94- ينظر : مشكل إعر اب القر آن: 492/2، و التنيان في إعراب القر آن: 941/2.

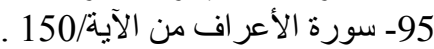

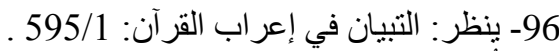

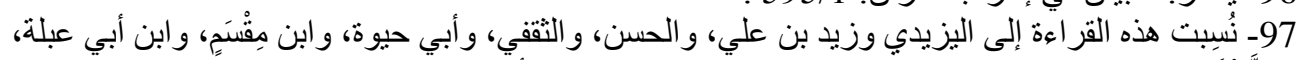

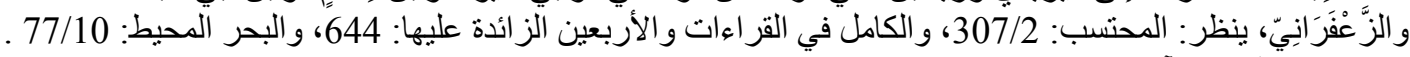

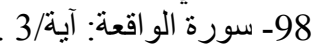

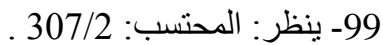

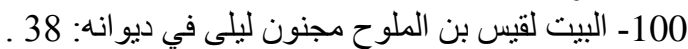

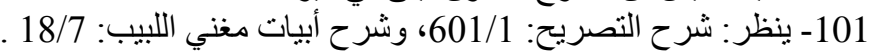


2020 سبتمبر

ISSN: $2415-4822$
Volume (15)

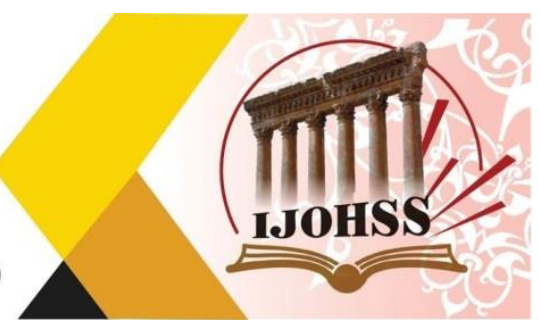

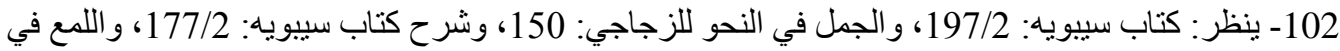

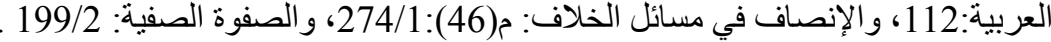

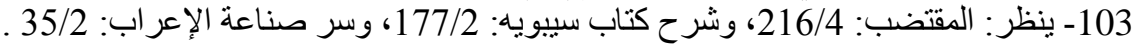

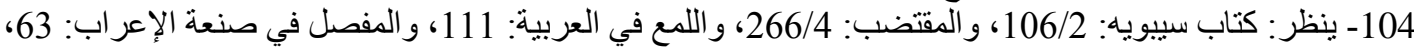

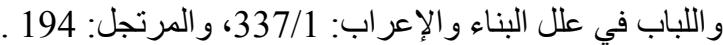

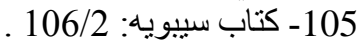
106- ينظر : شرح المفصّل: 323/1، وشر ح الرضى على الكافية: 376/1، و التعليقة على المقرّب: 274، و التذييل

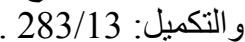
107- ينظر : شرح ابن الناظم على ألفية ابن مالك: 410، و اللمحة في شرح الملحة: 609/2-610، وشرح الأشموني: . 34/3

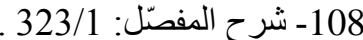

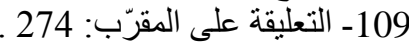

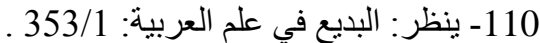

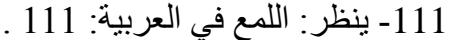

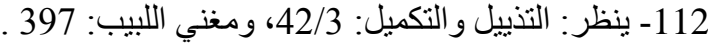

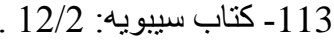
114 ينظر : الكناث في النحو و التصريف: 1113

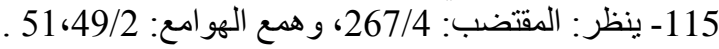

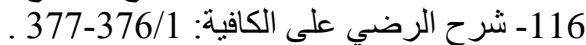

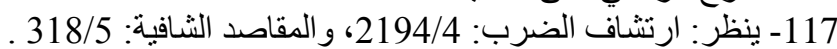

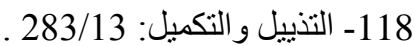

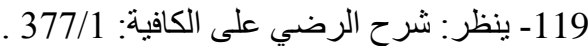

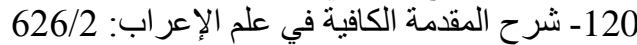
121- ينظر: كتاب سييو يه: 110/1، 169، 165، و الجمل في النحو للزجاجي: 85، و التوطئة: 262-263، وشرح الجمل لابن

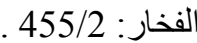

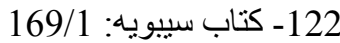
123- ينظر : شرح الجزولية للأبذي: 248 ـ 24

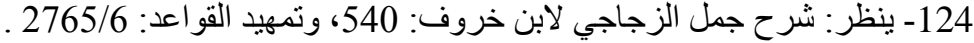

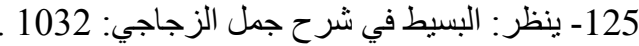

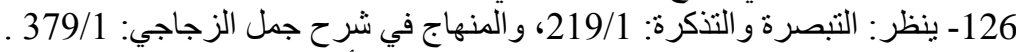

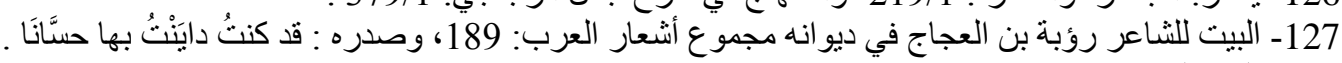

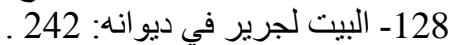

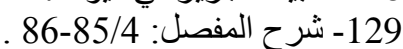
130- شرح الرضي على الكافية: 220/2 ـ الشفل

المصادر والمراجع القزآن الكريم

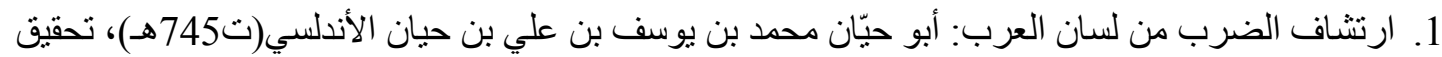

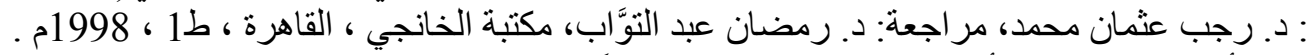

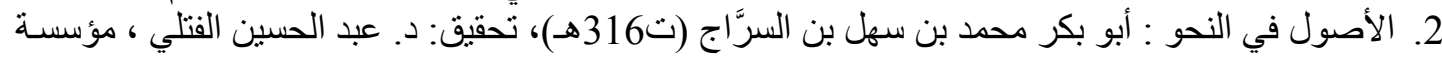

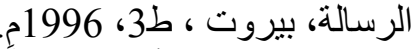
3. إعراب القرآن: أبو جعفر النََّّاس أحمد بن محمد المر ادي النحوي (ت338هـهـ)، وضع حواشيهه و علق عليه:

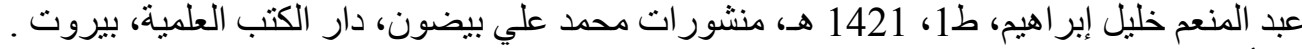

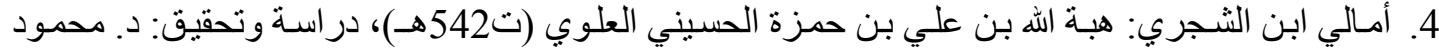
محمد الطناحي، مكتبة الخانجي، القاهرة، ط1 ، 1992م. 


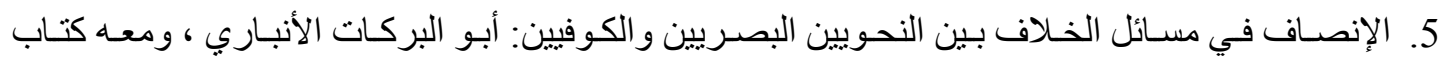

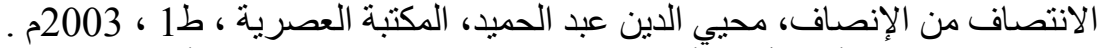

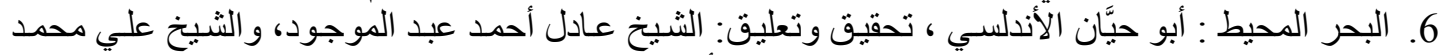

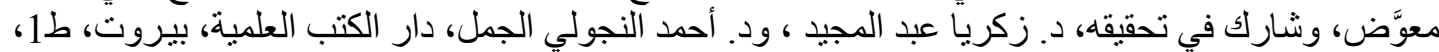
1993

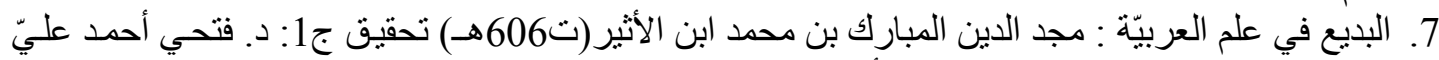

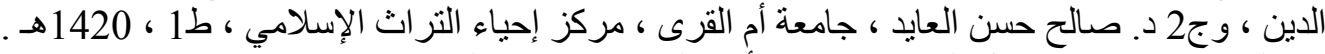

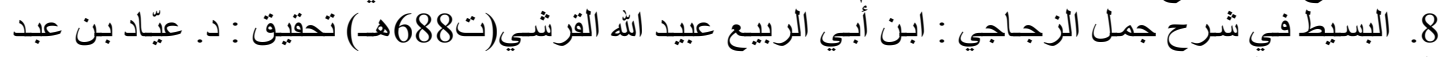

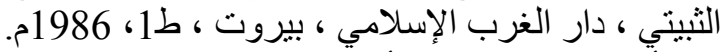

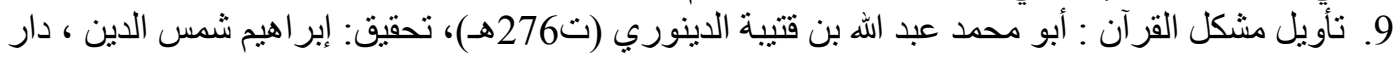

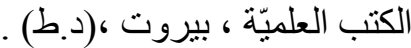
10. التبصرة و التذكرة : أبو محمد عبد الله بن علي التي الصيمري (من نحاة القرن الرابع الهجري) ، تحقيق : د.

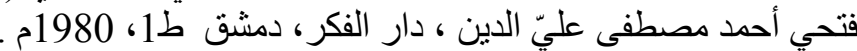

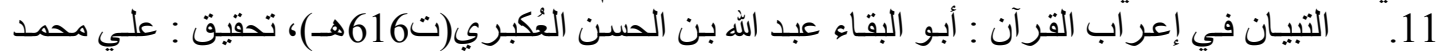

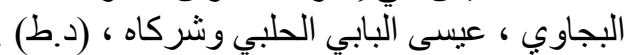
12.

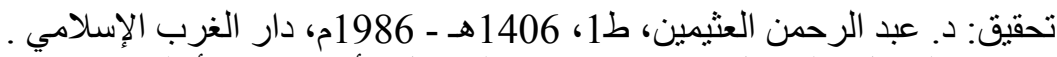
13.

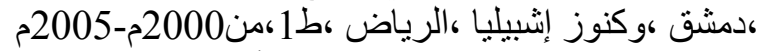
14. التعليقة على كتاب سيبويه : أبو علي الفارسي، تحقيق : عوض بن بن حمد القوزي ، ط1 ، 1990م -

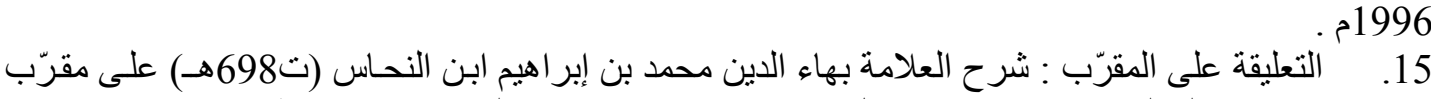

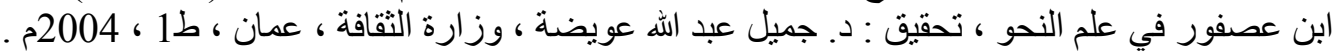

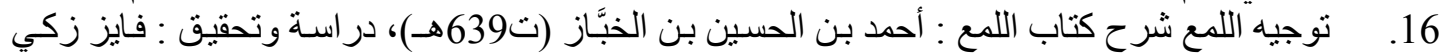

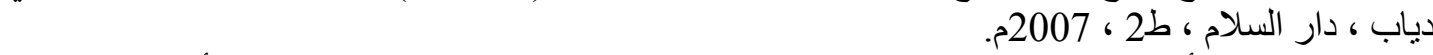
17. التوطئة : أبو علي عمر بن محمد الثلوبين (ت654هـ)، دراسة وتحقيق : د. يوسف أحمد المطوع ،

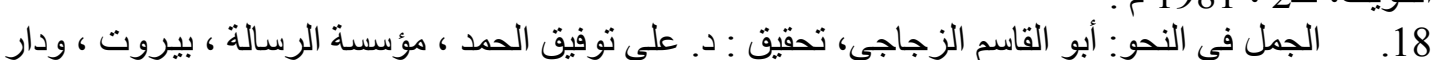

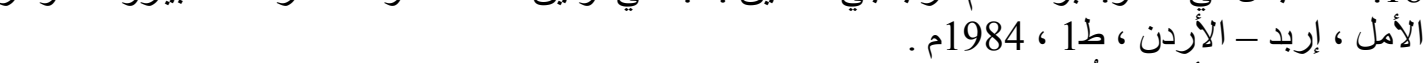

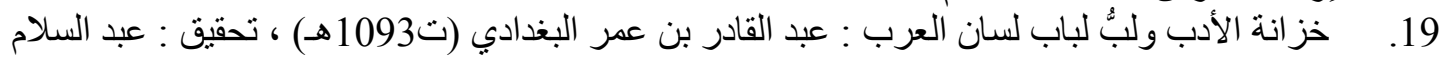

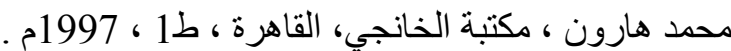

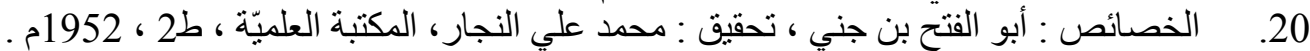

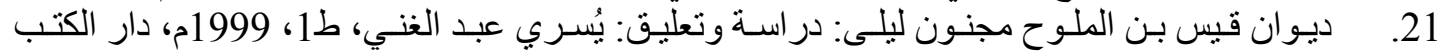
العلميّة، بيروت

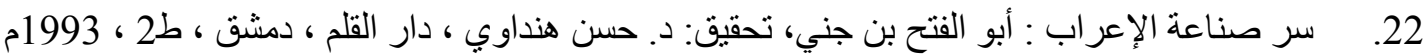

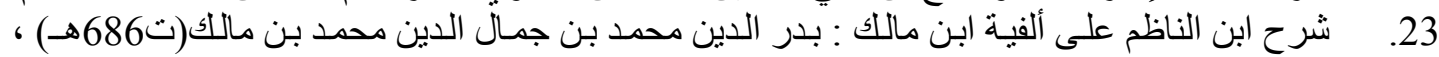

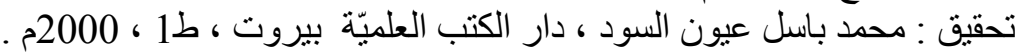

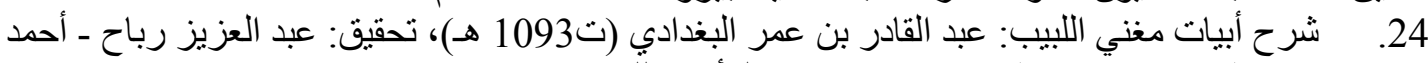

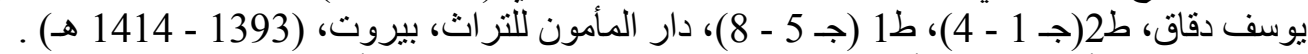

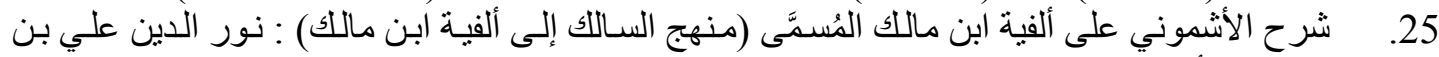

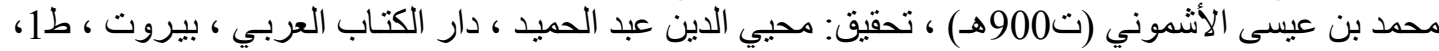

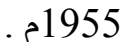

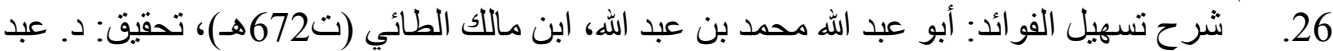

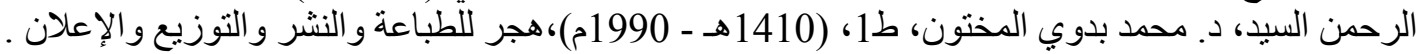


2020 سبتمبر

ISSN: $2415-4822$
Volume (15)
العدد (15)

September 2020

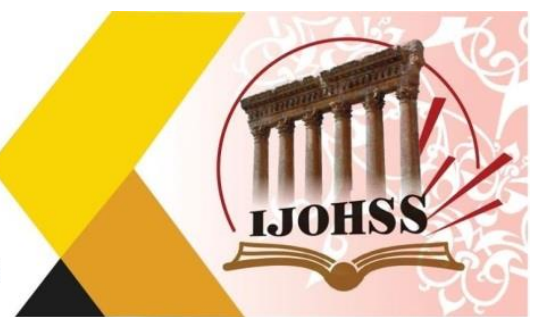

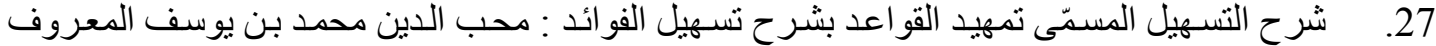

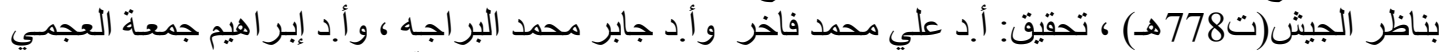

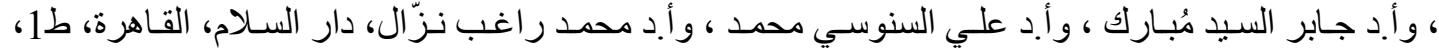
. 2007

28. شرح التصريح على التوضيح ، أو التصريح بمضمون التوضيح في النحو : الشيخ خالد بن عبداله باله

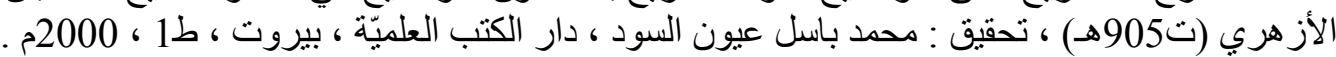

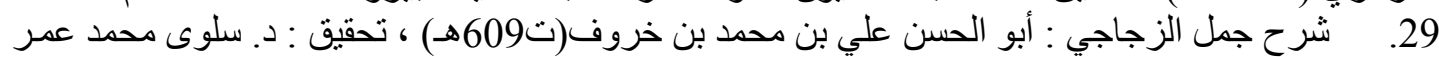

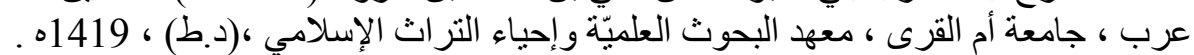

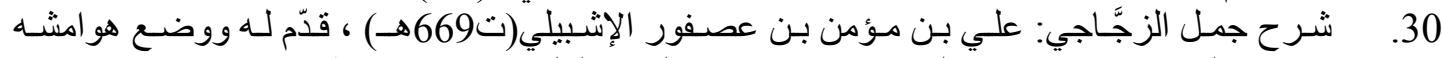

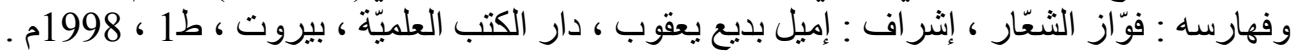

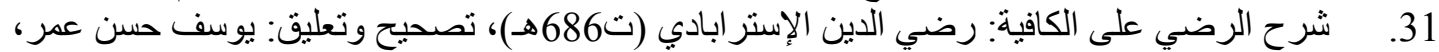

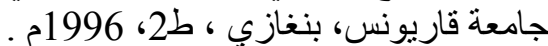
32. شرح شذور الذهب في معرفة كلام العرب: جمال الدين بن هشام ، اعتنى به: محمد أبو فضل عاثشور ،

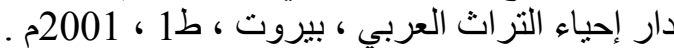
33. شرح الثو اهد الثنعرية في أمات الكتب النحوية : محمد بن محمد حسن شُرَّاب، ط1، 1427 هــ 2007

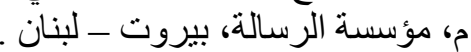

34. شرح الكافية الثافية : جمال الدين بن مالك، تحقيق: د. عبد المنعم أحمد هريري ، دار المأمون للتراث ،

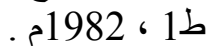

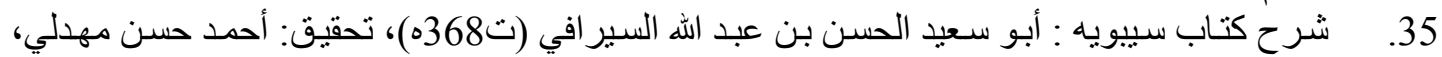

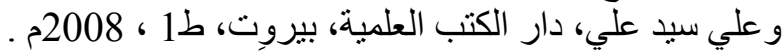

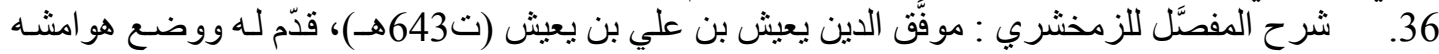

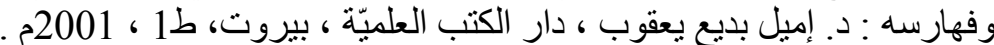

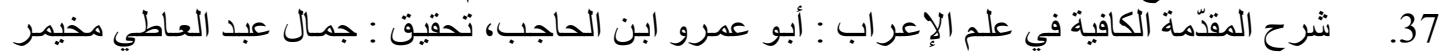

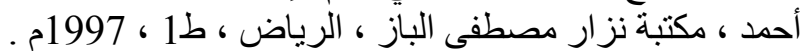

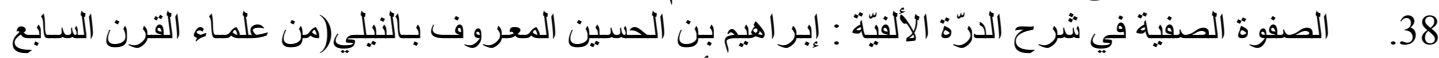

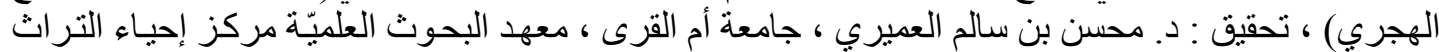

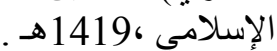

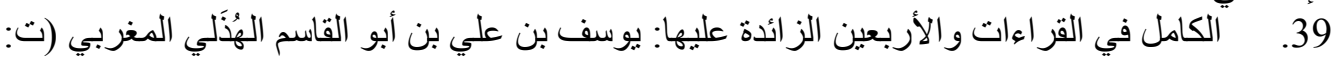

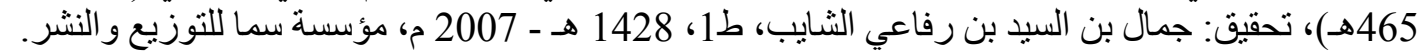

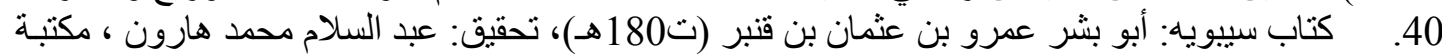

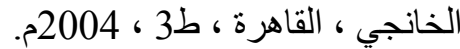

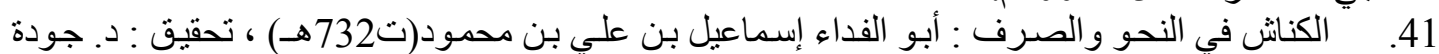

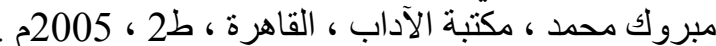

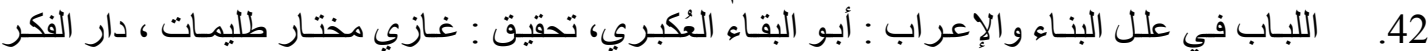

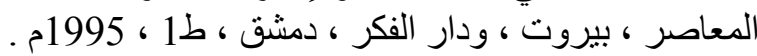

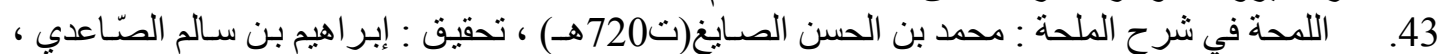

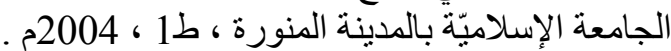

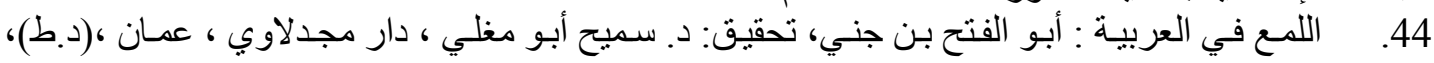

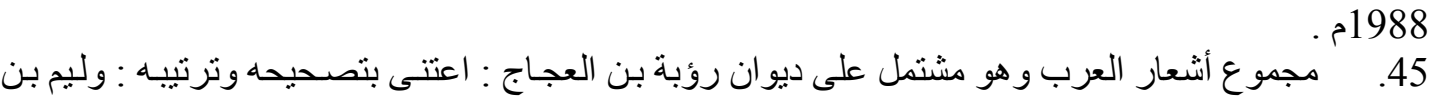

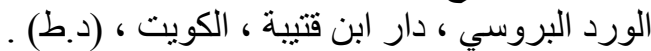

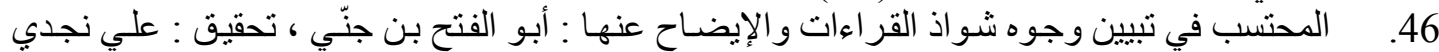
ناصف ، ود. عبد الحليم النجّار ، ود.عبد الفتاح شلبي ، إحياء التراث الإسلامي ، مصر ،(د.ط)، 1994م . 


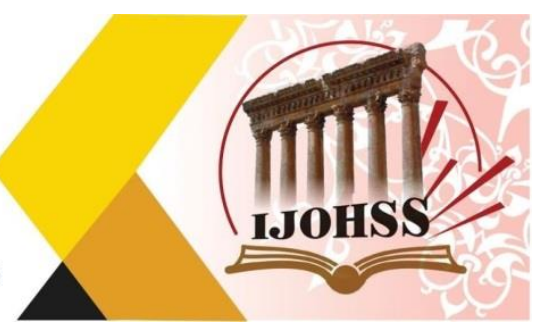

47. المرتجل في شرح الجمل: أبو محمد عبد الله بن أحمد ابن الخشـاب (ت567 هـ)، تحقيق ودراسـة: علي

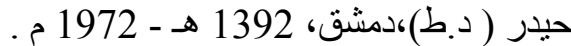

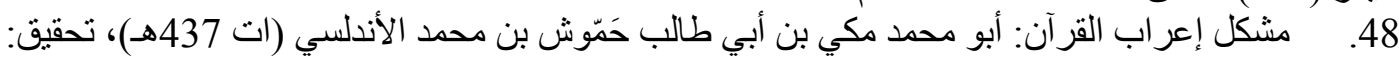

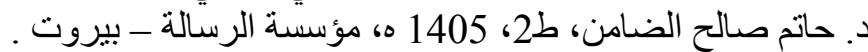

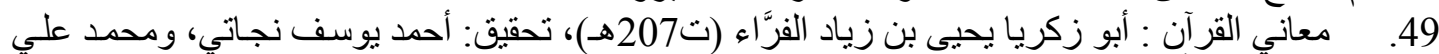

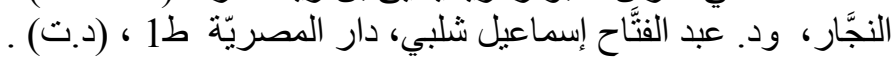

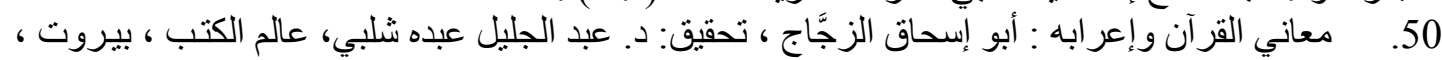

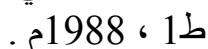

51. مغني اللبيب عن كتب الأعاريب : جمال الدين بن هشام الأنصاري ، تحقيق: د. مازن المبارك، ومحمد

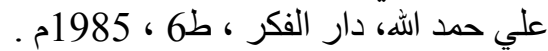

52. المفصَّل في صنعة الإعراب : جار الله الزمخشري ، تحقيق : د. علي بو ملحم ، مكتبـة الهلال ، بيروت

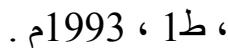

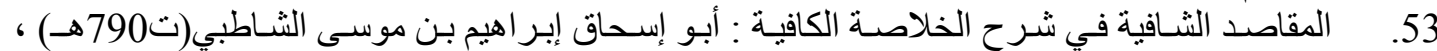

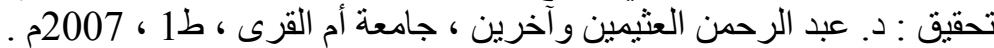

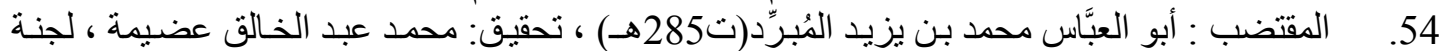

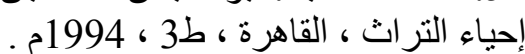

55

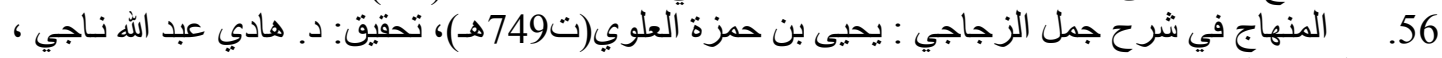

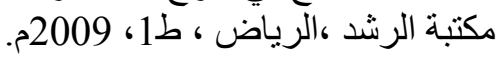

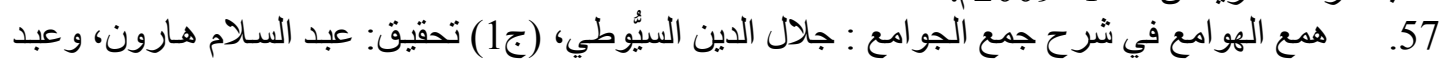

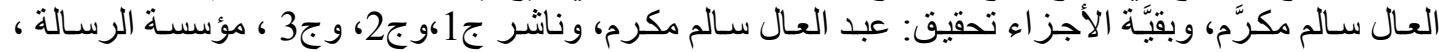

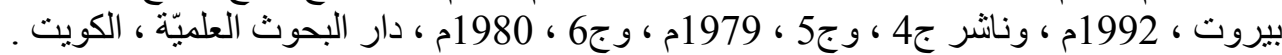

الرسائل والأطاريح 58. الأبذي ومنهجه في النحو مع تحقيق السفر الأول من شرحه على الجزوليّة، (أطروحة دكتور اه)، إعداد:

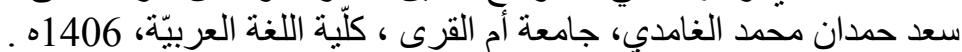

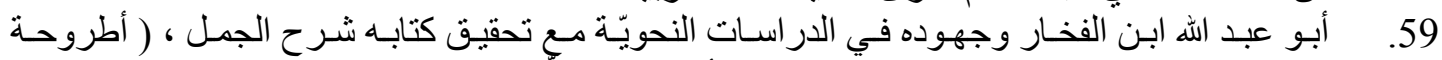

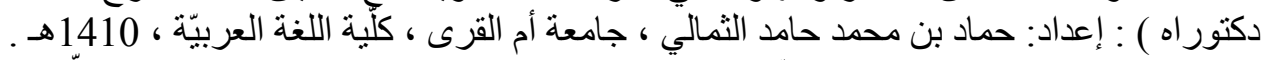
60.

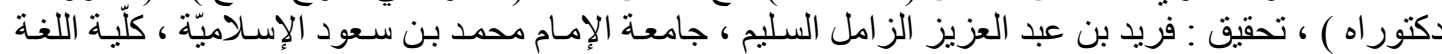

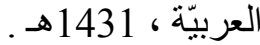

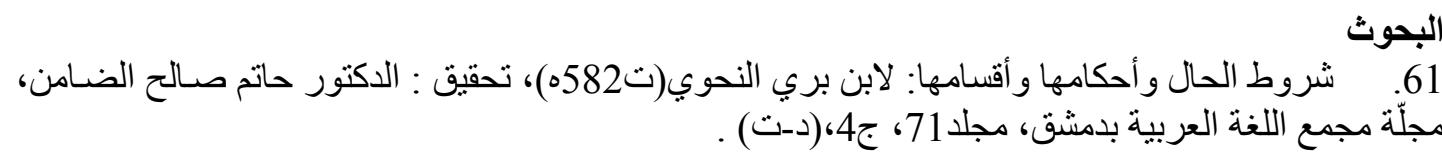




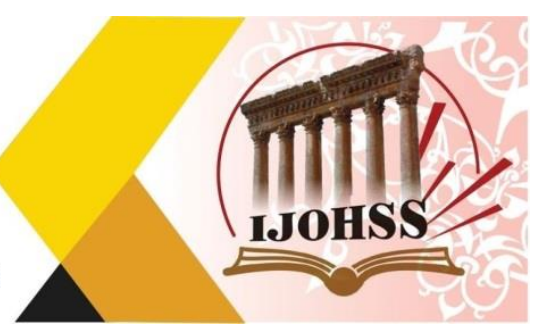

\section{References}

62. Resorption of beating from the tongue of the Arabs: Abu Hayyan Muhammad bin Yusuf bin Ali bin Hayyan Al-Andalusi (d. 745 AH), investigation: Dr. Ragab Othman Mohamed, review: d. Ramadan Abdel-Tawab, Al-Khanji Library, Cairo, I 1, 1998 AD.

63. Fundamentals in grammar: Abu Bakr Muhammad bin Sahel bin Al-Sarraj (d. 316 $\mathrm{AH}$ ), investigation: d. Abd al-Hussein al-Fatli, the Risala Foundation, Beirut, 3rd edition, 1996 AD.

64. The syntax of the Qur'an: Abu Ja'far al-Nahas Ahmad ibn Muhammad al-Muradi al-Nahw ((d. $338 \mathrm{AH})$, put his notes and commented on it: Abd al-Mun`m Khalil Ibrahim, i 1, 1421 AH, Muhammed Ali Beydun Publications, Dar al-Kutub al'Ilmiyya, Beirut.

65. Amali Ibn Al-Shajri: Gift of God bin Ali bin Hamza al-Husayni al-Alawi (d. 542 AH), study and investigation: d. Mahmoud Mohamed Al-Tanahi, Al-Khanji Library, Cairo, 1st edition, 1992 AD.

66. Fairness in matters of disagreement between the visual grammarians and the Kufic: Abu Al-Barakat Al-Anbari, and with him the book "The Equity of Equity," Mohiuddin Abdul-Hamid, The Modern Library, 1st edition, 2003 AD.

67. Surrounding Sea: Abu Hayyan Al-Andalusi, investigation and commentary: Sheikh Adel Ahmad Abdel-Mawgoud, and Sheikh Ali Muhammad Moawad, and participated in his investigation, d. Zakaria Abdul Majeed, and Dr. Ahmad Al-Najouli Al-Jamal, Dar Al-Kutub Al-Alami, Beirut, 1st edition, 1993 AD.

68. Budaiya in Arabic science: Majd al-Din al-Mubarak ibn Muhammad ibn al-Athir (d. $606 \mathrm{AH}$ ), achievement part 1: d. Fathi Ahmed Ali al-Din, c 2 d. Saleh Hassan AlAyed, Umm Al-Qura University, Center for the Revival of Islamic Heritage, I 1, 1420 AH.

69. The simple one in explaining Jamal Al-Zajaji: Ibn Abi Al-Rabi 'Ubaid Allah AlQurashi (d. 688 AH). Ayad bin Abd Al-Thebaiti, Dar Al-Gharb Al-Islami, Beirut, 1st edition, 1986 AD.

70. Interpretation of the problem of the Qur'an: Abu Muhammad Abdullah bin Qutaybah al-Dinuri (d. $276 \mathrm{AH}$ ), investigation: Ibrahim Shams al-Din, Dar al-Kutub al-Alami, Beirut, .

71. Insight and reminder: Abu Muhammad Abdullah bin Ali al-Simari (from the fourth century AH AH), by: Fathi Ahmad Mustafa Ali al-Din, Dar al-Fikr, Damascus, 1st edition, 1980 AD.

72. Clarification in the Qur'anic syntax: Abu al-Baqa 'Abdullah bin al-Hasan alAkbari (d. $616 \mathrm{AH}$ ), investigation: Ali Muhammad al-Bajawi, Issa al-Babi al-Halabi and Co., .

73. Explaining the doctrines of the grammatical and optical Kufic: Abu Al-Baqaa Abdullah bin Al-Hussein Al-Akbari (d. 616 AH), investigation: Dr. Abdul Rahman Al-Othaimeen, 1st edition, 1406 AH - 1986 AD, Islamic Dar Al-Gharb.

74. Appendix and complement in explaining the facilitation book: Abu Hayyan AlAndalusi, investigation d. Hassan Hindawi, Dar Al-Qalam, Damascus, and the treasures of Seville, Riyadh, 1st edition, from 2000-2005 AD 


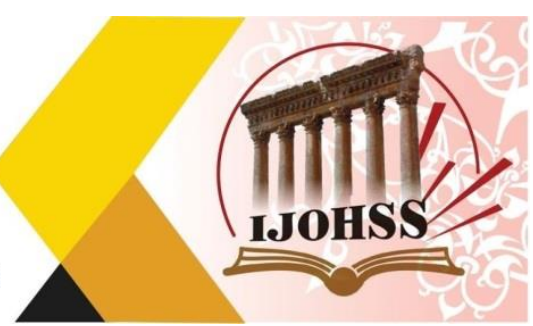

75. Commentary on Sibawayh's book: Abu Ali Al-Farsi, investigation: Awad bin Hamad Al-Qouzi, 1st edition, 1990 -1996AD.

76. Commentary on Al-Muqarrab: Explanation of the scholar Bahaa Al-Din Muhammad Ibn Ibrahim Ibn Al-Nahhas (d. 698 AH) on the approach of Ibn Asfour in grammar science, investigation: Jamil Abdullah Aweidah, Ministry of Culture, Amman, 1st edition, 2004 AD.

77. Guidance of the Shining Explanation of the Book of Shining: Ahmed bin AlHussein bin Al-Khabbaz (d. 639 AH), study and investigation: Fayez Zaki Diab, Dar Al-Salam, 2nd edition, 2007 AD.

78. Foreword: Abu Ali Omar bin Muhammad Al-Shalobin (d. 654 AH), study and investigation: Dr. Yousef Ahmad Al-Mutawa, Kuwait, 2nd edition, 1981 AD.

79. The sentences in grammar: Abu al-Qasim Al-Zajaji, investigation: Dr. Ali Tawfiq Al-Hamad, Al-Resala Foundation, Beirut, and Dar Al-Amal, Irbid - Jordan, 1st edition, 1984 AD.

80. Treasury of Literature and the core of the door of the tongue of the Arabs: Abdul Qadir bin Omar Al-Baghdadi (d. 1093 AH), investigation: Abdul Salam Muhammad Harun, Al-Khanji Library, Cairo, 1st edition, 1997 AD.

81. Characteristics: Abu al-Fath bin Jenny, investigation: Muhammad Ali al-Najjar, the Scientific Library, 2nd edition, 1952 AD.

82. Diwan Qais Bin Al-Mallouh Majnoon Laila: A Study and Commentary: Yusri Abdel-Ghani, 1st edition, 1999 AD, Scientific Books House, Beirut

83. The Secret of Making the Expression: Abu Al-Fath Bin Jani. Hassan Hindawi, Dar Al-Qalam, Damascus, 2nd edition, 1993 AD.

84. Explanation of Ibn al-Nazim on the millennium of Ibn Malik: Badr al-Din Muhammad bin Jamal al-Din Muhammad bin Malik (d. $686 \mathrm{AH}$ ), investigation: Muhammad Basil Ayoun al-Aswad, Dar al-Kutub al-Alamiyya, Beirut, 1st edition, 2000 AD.

85. Explanation of the verses of Mughni al-Labib: Abdel-Qader bin Omar AlBaghdadi (d. 1093 AH), investigation: Abdel Aziz Rabah - Ahmed Youssef Daqqaq, 2nd edition (c 1-4), 1st edition (c 5-8), Dar Al Mamoun Heritage, Beirut, (1393 - 1414 $\mathrm{AH})$.

86. Explanation of Al-Ashmoni on the Millennium of Ibn Malik Al-Muamed (The Approach of the Traveler to the Millennium of Malik): Nur al-Din Ali bin Muhammad bin Isa al-Ashmoni (d. $900 \mathrm{AH}$ ), investigation: Muhyiddin Abd alHamid, Dar al-Kitab al-Arabi, Beirut, i 1, 1955 CE.

87. Explanation of Facilitating Benefits: Abu Abdullah Muhammad bin Abdullah, Ibn Malik Al-Ta'i (d. 672 AH), investigation: Dr. Abdul Rahman Al-Sayed, d. Muhammad Badawi Al-Mukhtoon, 1st edition (1410AH-1990AD), deserted for printing, publishing, distribution and advertising.

88. Explanation of the facility called Paving the Rules Explaining the Facilitation of Benefits: Muheb al-Din Muhammad bin Yusuf, known as the headmaster of the army (d. 778 AH), by: Prof. Ali Muhammad Fakhir, Prof. Jaber Muhammad al-Barajeh, Prof. Ibrahim Jaber al-Ajami, and Prof. Jaber al-Sayyid Mubarak Prof. Ali Al-Senussi 


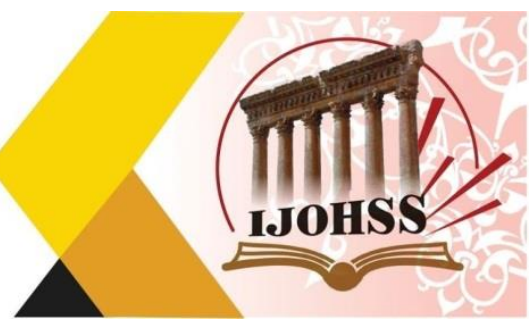

Muhammad, and Prof. Mohammed Ragheb Nazzal, Dar Al-Salam, Cairo, Ed. 1, 2007 AD.

89. Explanation of the statement on the clarification, or the statement of the content of the clarification in the manner: Sheikh Khaled bin Abdullah Al-Azhari (d. 905 $\mathrm{AH}$ ), investigation: Muhammad Basil Oyoun Al-Aswad, Dar Al-Kutub Al-Alumiya, Beirut, 1st edition, $2000 \mathrm{AD}$.

90. Explanation of Jamal al-Zajaji: Abu al-Hasan Ali bin Muhammad bin Kharouf (d. 609 AH), investigation: Dr. Salwa Muhammad Omar Arab, Umm Al-Qura University, Institute for Scientific Research and the Revival of Islamic Heritage, , $1419 \mathrm{AH}$.

91. Explanation of Jamal Al-Zajaji: Ali bin Moamen bin Asfour Al-Eshbili (d. 669 $\mathrm{AH})$, presented to him and set his margins and indexes: Fawaz Al-Shaar, Supervision: Emile Badi 'Yaqoub, Dar Al-Kutub Al-Alamiya, Beirut, 1st edition, 1998 AD.

92. Explanation of al-Radhi on Adequacy: Radhi al-Din al-Istrabadi (d. $686 \mathrm{AH}$ ), Correction and Commentary: Youssef Hassan Omar, Garyounis University, Benghazi, 2nd edition, 1996 AD.

93. Explanation of the gold nuggets in knowing the words of the Arabs: Jamal AlDin Bin Hisham, taken care of by: Muhammad Abu Fadl Ashour, House of Arab Heritage Revival, Beirut, I 1, 2001 AD.

94. Explanation of poetic evidence in the death of grammatical books: Muhammad bin Muhammad Hassan Sharab, 1st edition, 1427 AH - 2007 AD, Al-Resala Foundation, Beirut - Lebanon.

95. Explanation of adequate healing: Jamal al-Din bin Malik, investigation: d. AbdelMoneim Ahmed Hariri, Dar Al-Maamoun for Heritage, 1st edition, 1982 AD.

96. Explanation of Sibawayh's book: Abu Saeed Al-Hassan Bin Abdullah Al-Serafi (d. 368 AH), investigation: Ahmed Hassan Mahdali, and Ali Sayyid Ali, Scientific Books House, Beirut, 1st edition, 2008 AD.

97. Detailed explanation of Al-Zamakhshari: Muwaffaq al-Din Yaish bin Ali bin Yaish (d. $643 \mathrm{AH}$ ), present it to him and set his margins and indexes: Dr. Emile Badi 'Yaqoub, Dar Al-Kutub Al-Alami, Beirut, 1st edition, 2001 AD.

98. Explanation sufficient introduction in the science of Arabization: Abu Amr Ibn Al-Hajeb, investigation: Jamal Abdul Ati Mukhaimir Ahmed, Nizar Mustafa Al-Baz Library, Riyadh, I 1, 1997 AD.

99. Elite elitism in explaining the millennium Dora: Ibrahim bin Al-Hussein known as the Nile (from the scholars of the seventh century AH), investigation: d. Mohsen bin Salem Al-Omairi, Umm Al-Qura University, Institute for Scientific Research, Center for the Revival of Islamic Heritage, 1419 AH.

100.Al-Kamil in the forty recited surrogates: Yusef bin Ali bin Abu al-Qasim alHudhali al-Mughrabi (Tel: $465 \mathrm{AH}$ ), investigation: Jamal bin al-Sayyid bin Rifai alShayib, 1st edition, 1428 AH - 2007 CE, Sama Foundation for Distribution and Publishing.

101.Sibawayh Book: Abu Bishr Amr bin Othman bin Qanbar (d. $180 \mathrm{AH}$ ), investigation: Abdul Salam Muhammad Harun, Al-Khanji Library, Cairo, 3rd edition, 2004 AD. 


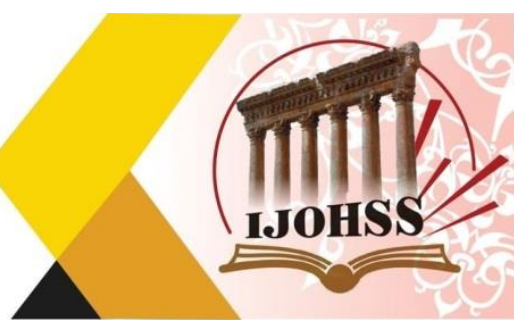

102.Kanash in grammar and exchange: Abu al-Fedaa Ismail bin Ali bin Mahmoud (d. $732 \mathrm{AH}$ ), investigation: d. Gouda Mabrouk Mohamed, Library of Arts, Cairo, 2nd edition, 2005 AD.

103.The core of construction and syntactic ills: Abu al-Waqqa al-Akbari, investigation: Ghazi Mukhtar Tulaimat, House of Contemporary Thought, Beirut, and House of Thought, Damascus, 1st edition, 1995 AD.

104.The Glance in Explaining the Salt: Muhammad Bin Al-Hassan Al-Sayegh (d. 720 $\mathrm{AH}$ ), investigation: Ibrahim bin Salem Al-Saadi, Islamic University of Madinah, 1st edition, 2004 AD.

105.Shining in Arabic: Abu Al-Fateh Bin Jani, investigation: Dr. Samih Abu Mughali, Dar Majdalawi, Amman, , 1988 AD.

106. The collection of the poems of the Arabs, which includes the Diwan of Rabwah bin Al-Ajaj: He took care of his correction and arrangement: William bin Al-Ward Al-Prussi, Dar Ibn Qutaiba, Kuwait, .

107.Calculated in explaining the faces of gay porn and reading about it: Abu Al-Fath bin Jenni, investigation: Ali Najdi Nassef, and Dr. Abdel-Halim Al-Najjar, and Dr. Abdel-Fattah Shalaby, Islamic Heritage Revival, Egypt, , 1994 AD.

108. The improviser in explaining the sentences: Abu Muhammad Abdullah bin Ahmed Ibn al-Khashab (d. $567 \mathrm{AH}$ ), investigation and study: Ali Haider (d.), Damascus, 1392 AH - 1972 CE.

109.The problem of the parsing of the Qur'an: Abu Muhammad Makki bin Abi Talib Hammoush bin Muhammad al-Andalusi (c. 437 AH), by: Hatem Saleh Al-Damen, 2nd edition, $1405 \mathrm{AH}, \mathrm{Al}-$ Resala Foundation - Beirut.

110.The meanings of the Qur'an: Abu Zakaria Yahya bin Ziyad al-Farra (d. 207 AH), by: Ahmed Yusef Najati, Muhammad Ali Najjar, and Dr. Abdel-Fattah Ismail Shalaby, Dar Al-Masrya, 1st edition, (N.D.).

111.The meanings of the Qur'an and its syntax: Abu Ishaq al-Zajaj, investigation: $d$. Abd al-Jalil Abdo Shalabi, World of Books, Beirut, 1st edition, 1988 AD.

112.Mughni al-Labib, on the books of Arabism: Jamal al-Din bin Hisham al-Ansari, investigation: d. Mazen Al-Mubarak, and Muhammad Ali Hamad Allah, Dar Al-Fikr, 6th edition, $1985 \mathrm{AD}$.

113.Detailed in the syntax of the syntax: Jarallah Al-Zamakhshari, investigation: Dr. Ali Bu Melhem, Al-Hilal Library, Beirut, 1st edition, 1993 AD.

114.The healing purposes in explaining the adequate summary: Abu Ishaq Ibrahim bin Musa Al-Shatby (d. 790 AH), investigation: d. Abdul Rahman Al-Othaimeen and others, Umm Al-Qura University, 1st edition, 2007 AD.

115.Summary: Abu al-Abbas Muhammad bin Yazid al-Mubarrad (d. 285 AH), investigation: Muhammad Abd al-Khaliq Adima, Committee for the Revival of Heritage, Cairo, 3rd edition, 1994 AD.

116.The Salik Approach to the Millennium of Malik Ibn Malik: Abu Hayyan AlAndalusi, Adwa 'Al-Salaf (d. I.)

117.The curriculum in explaining Jamal Al-Zajaji: Yahya bin Hamza Al-Alawi (d. 749 AH), by: Dr. Hadi Abdullah Naji, Al-Rushd Library, Riyadh, 1st edition, 2009 AD. 
118.The deafness of the mosques in explaining the gathering of the mosques: Jalal alDin al-Suyuti, (Part 1) Inquiry: Abd al-Salam Haroun, Abd al-Al Salem Salem Makram, and the rest of the parts. , J5, 1979 AD, and J6, 1980 AD, Scientific Research House, Kuwait.

\section{Messages and thesis}

119.Al-Abadhi and his method in grammar with the achievement of the first book of his commentary on Jazuli, (PhD thesis), Prepared by: Saad Hamdan Muhammad AlGhamdi, Umm Al-Qura University, College of Arabic Language, 1406 AH.

120.Abu Abdullah Ibn Al-Fakhar and his efforts in grammatical studies with the achievement of his book Sharh Al-Jamal, (PhD thesis): Prepared by: Hammad bin Muhammad Hamid Al-Thamali, Umm Al-Qura University, College of Arabic Language, $1410 \mathrm{AH}$.

121.Grammatical thought by Ibn Al-Dahan (d. 569 AH), with the fulfillment of his book (Al-Ghurrah Sharh Al-Lama '): (PhD thesis), investigation: Farid bin Abdul Aziz Al-Zamil Al-Saleem, Imam Muhammad bin Saud Islamic University, College of Arabic Language, $1431 \mathrm{AH}$.

\section{Research}

122.Conditions, provisions and sections of the case: by Ibn Birri Al-Nahwi (d. 582 $\mathrm{AH}$ ), investigation: Dr. Hatem Salih Al-Damen, Journal of the Arabic Language Academy, Damascus, volume 71, part 4, (N.D). 